\title{
Process-based modelling of decadal trends in growth, survival, and smolting of wild salmon (Salmo salar) parr in a Scottish upland stream
}

\author{
William S.C. Gurney, Philip J. Bacon, Graham Tyldesley, and Alan F. Youngson
}

\begin{abstract}
This paper reports a new model of the freshwater stages of an anadromous fish, at the core of which is a stochastic description of the size-at-age dynamics of a growing cohort. Emigration is assumed to require the individual to exceed a threshold size at a critical time of year, thus making the distributions of survival to, and age at, smolting emergent properties of the model. The model is applied to a long-term data set on juvenile Atlantic salmon (Salmo salar) in the Girnock Burn, Scotland, to understand the role played by decadal temperature trends in generating changes in smolt production and age distribution. We conclude that changes in age at smolting are compatible with causation by shifts in the temperature regime. However, the large attenuation between a dramatic fall in spawner numbers and a relatively minor diminution in total smolt production does not result from the physiological effects of temperature but is rather a result of strongly density-dependent mortality between the deposition of ova and the appearance of catchable fry the following summer.

Résumé : Notre étude présente un nouveau modèle des stades d'eau douce d'un poisson anadrome qui contient comme élément central une description stochastique de la dynamique de la taille en fonction de l'âge chez une cohorte en croissance. On présume que l'émigration n'est possible que lorsqu'un individu a dépassé une taille seuil à un moment critique de l'année, ce qui fait que les distributions des survies jusqu'à la transformation en saumoneau et des âges lors de cette transformation sont des propriétés émergentes du modèle. Nous utilisons le modèle pour l'analyse qu'une banque de données à long terme sur les jeunes saumons atlantiques (Salmo salar) de Girnock Burn, Écosse, afin de comprendre le rôle joué par les tendances décennales de température dans les changements survenus dans la production de saumoneaux et la distribution des âges. Nous concluons que les changements observés dans l'âge de la transformation en saumoneau sont compatibles avec une causalité reliée aux modifications du régime thermique. Cependant, la forte atténuation entre la chute spectaculaire des nombres de reproducteurs et la diminution relativement mineure de la production totale de saumoneaux n'est pas due aux effets physiologiques de la température, mais s'explique plutôt par la mortalité fortement dépendante de la densité entre le dépôt des oeufs et l'apparition d'alevins récoltables l'été suivant.
\end{abstract}

[Traduit par la Rédaction]

\section{Introduction}

\section{Overview}

Most salmon species are anadromous, and many form the target of economically important sport and commercial fisheries. Apart from generalized restriction of catches, management actions on salmon populations at sea are complicated by jurisdictional issues and the complexities of differentiating breeding stocks. In contrast, the life-history stages between return of the adults to the river of their birth and emigration of their offspring to sea as smolts are readily accessible.

Effective management of the riverine component of a sal- mon stock requires an understanding of a complex of processes. The best studied of these is parr growth, which has been the subject of a number of laboratory investigations (Elliott and Hurley 1997; Metcalfe 1998), as well as observation and empirical analysis in the wild (Erkinaro and Niemela 1995; Strothotte et al. 2005; Jutila et al. 2006). Factors known to affect freshwater growth of Atlantic salmon include temperature, food availability, and density (Gibson 1993; Elliott and Hurley 1997; Grant et al. 1998). A relationship between mean age at smoltification and the combination of temperature and day length has been demonstrated across the range of Atlantic salmon by Metcalfe and Thorpe (1990).

Despite this level of empirical study, no process-based

W.S.C. Gurney. ${ }^{\mathbf{1}}$ Department of Statistics and Modelling Science, University of Strathclyde, Glasgow G1 1XH, Scotland; Fisheries Research Services, Freshwater Fisheries Laboratory, Faskally, Pitlochry PH16 5LB, Scotland.

P.J. Bacon and A.F. Youngson. Fisheries Research Services, Freshwater Fisheries Laboratory, Faskally, Pitlochry PH16 5LB, Scotland. G. Tyldesley. Department of Statistics and Modelling Science, University of Strathclyde, Glasgow G1 1XH, Scotland.

${ }^{1}$ Corresponding author (e-mail: bill@stams.strath.ac.uk). 
model is available relating smolt output to the number of adults returning to spawn and the physical and biotic environment experienced by their developing offspring. The stochastic model framework described by Gurney and Veitch (2007) and Gurney et al. (2007) provides a natural platform upon which such a model can be constructed. In this paper, we report a unified dynamic description based on this framework, which covers the entire river phase of the life of an anadromous fish, including recruitment of fry from previously deposited ova, stochastically varying growth and survival of juvenile individuals, and emigration to sea.

We apply this model to a four-decade series of observations of juvenile Atlantic salmon in the Girnock Burn in northeastern Scotland. These data show the number of female spawners decreasing greatly between 1967 and 2003, while smolt production remains almost constant. Over the same period, the mean age at smolting has decreased markedly. The proximate question to which we address ourselves is one that only a process-based model can answer, namely, the relative importance of temperature trends and density-dependent regulation in maintaining smolt production against a large drop in spawner numbers. We are able to conclude that the observed changes in age at smolting are entirely consistent with temperature-induced shifts in growth performance. However, the concomitant changes in survival from fry to smolt, while helpful, play a relatively minor role in maintaining total smolt production compared with the density-dependent regulation evident between ova and fry and the beneficial effects of a recent policy of supportive manipulation of ova distribution within the stream.

\section{The data}

The Girnock Burn is a $9.5 \mathrm{~km}$ long, upland tributary of the River Dee, Aberdeenshire, Scotland, the hydraulic characteristics of which have been described by Malcolm et al. (2002). It is an active spawning ground for Atlantic salmon, the spawning habitat use of which has been documented by Moir et al. (1998). In the mid-1960s, a pair of fixed traps was constructed by Fisheries Research Services Freshwater Laboratory (FRS-FL) staff at Littlemill, near its confluence with the main stem of the Dee. The adult trap catches all returning adults, which are counted and sexed, their fork lengths are measured, and their scales are taken for age determination, before release upstream. The smolt trap catches a large proportion of emigrating juveniles, which are counted, their fork lengths are measured, and one in five is scaled for age determination, before release downstream.

For the avoidance of ambiguity, we define river age as the time from 1 January in the year in which the individual hatched. Using this definition, juvenile salmon aged between one and four years emigrate from the Girnock during two main periods (Youngson et al. 1983) — the spring smolting season (March to May) and an autumn parr run (October to December). Tagging studies (Youngson et al. 1994) show the autumn parr to be seaward migrants that are closely associated with the following smolt run and that contribute roughly pro rata to subsequent adult recruitment.

Between 1969 and 1980, the smolt trap was manned almost daily. Most fish were found to move out on high flows on dark nights, so more recent practice concentrates daily visits on the periods of adult return and juvenile emi-
Fig. 1. Spawning and emigration in the Girnock Burn between 1967 and 2003. (a) Adult female spawners, with grilse indicated by the dotted line and multi-sea-winter fish indicated by the solid line. (b) Total emigrant production (solid line), with younger emigrants (river age at emigration $<2.5$ years) shown by the dotted line and older emigrants (river age at emigration $>2.5$ years) shown by the broken line.

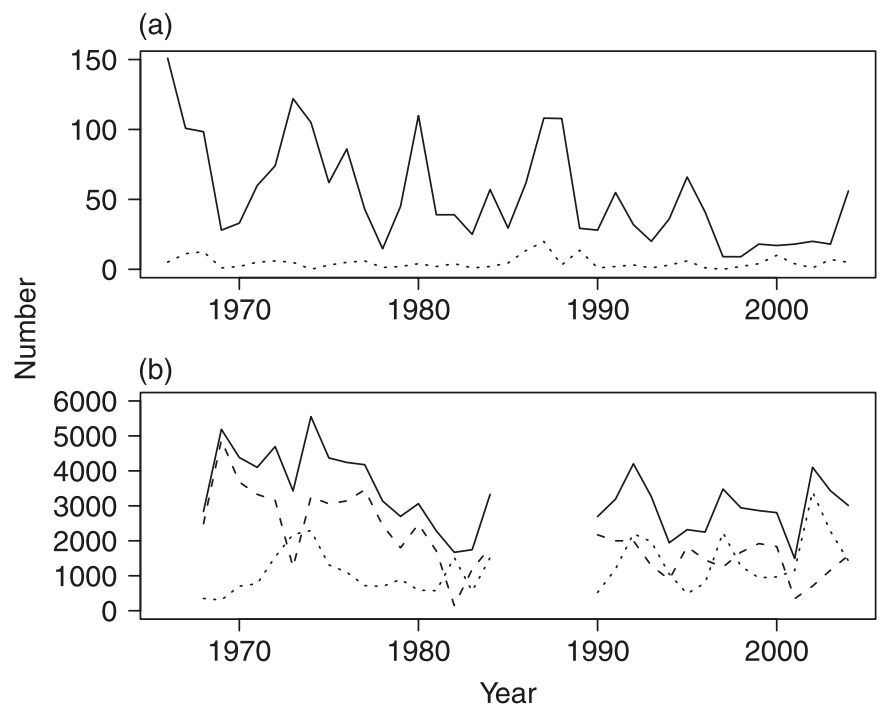

gration, with less frequent visits at other times. In spring, the trap rarely spills and loses few fish. During autumn spates, fallen leaves can block the trap, causing uncontrolled spillage and unquantified fish loss. Because of this difficulty, traditional indices of juvenile production at the Girnock have been based on the spring smolt run alone. However, this study is concerned with the overall demographics of the transition from ova to smolts, and so we need to include the autumn (parr) emigrant data. To avoid confusion, we shall refer to all riverine salmon (juveniles and precocious males) leaving the Girnock as emigrants.

In common with a number of other salmon rivers in the United Kingdom and elsewhere, the number of multi-seawinter fish returning annually to spawn in the Girnock (comprising the great majority of the female breeding stock) has shown a dramatic downward trend over the past 40 years (Fig. 1a, solid line), with yearly mean returns falling from 83.6 individuals (1966 to 1976) to 24.7 (1990 to 2000). Over the same period, the output of juvenile emigrants from the system has fallen only slightly (Fig. $1 b$, solid line), with a yearly mean of 4310 individuals before 1977 and 2808 individuals between 1993 and 2003.

Thus, over the four decades of this survey, spawner numbers have declined by $70 \%$, whereas smolt production has decreased by only $35 \%$. During the same period, however, the age at smolting of successive cohorts has changed dramatically (Fig. 1b, dotted and broken lines). In the late 1960s and early 1970s, the great majority of the emigrants departed from the Girnock at river ages in excess of 2.5 years, whereas by the $1990 \mathrm{~s}$, the numbers of emigrants with river ages above and below 2.5 years were approximately equal.

To obtain a more demographically precise view of these changes, we focus on the properties of cohorts (year classes) 
Fig. 2. Trends in emigrant size and age by cohort (year of hatch) between 1967 and 2003. Frames $(a)$ and $(b)$ show the proportion of the cohort emigrating at different ages. The light line in frame $(a)$ shows the proportion emigrating with river ages 1.5 to 2 , while the heavy line shows the proportion emigrating aged 2 to 2.5. The light and heavy lines in frame $(b)$ show the proportion of emigrants ages 2.5 to 3 and 3 to 3.5, respectively. Frame $(c)$ shows the size of individuals from given cohorts emigrating aged 1.5 to 2 (light dotted), 2 to 2.5 (light solid), 2.5 to 3 (heavy dotted), and 3 to 3.5 (heavy solid). Frame $(d)$ shows the length variability of the same groups of emigrants.

(a)

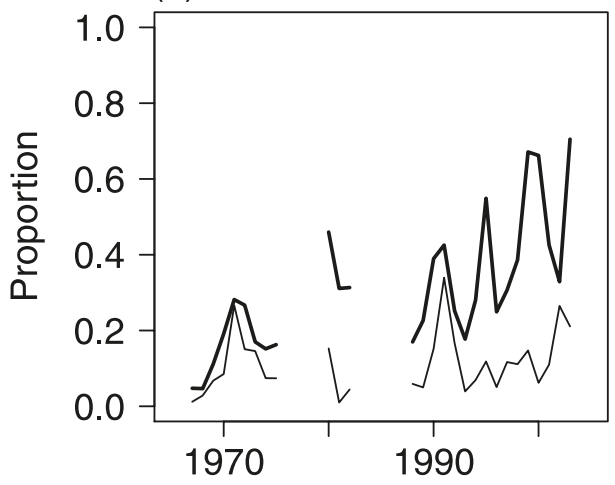

(c)

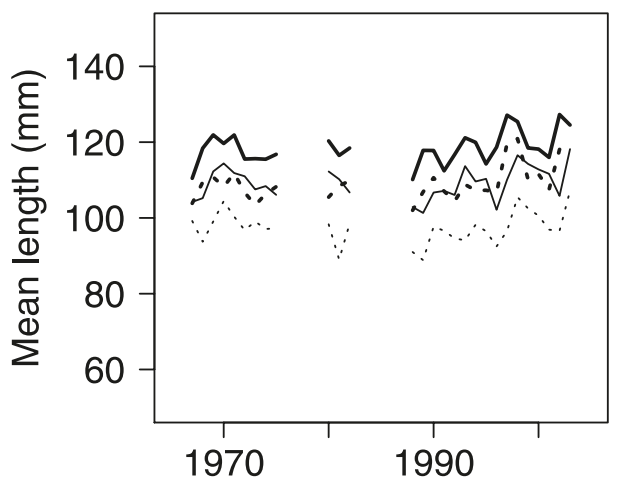

(b)

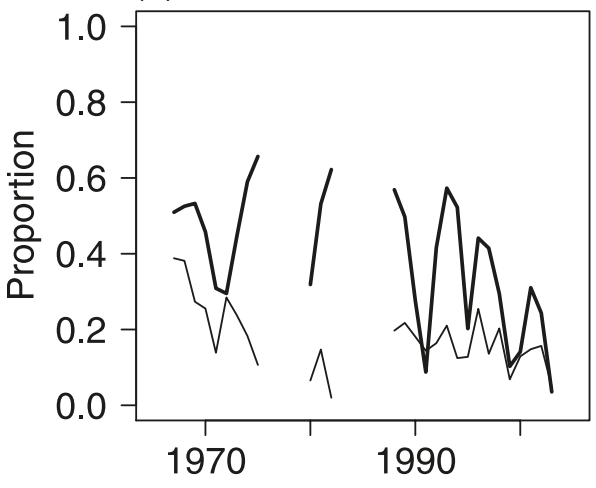

(d)

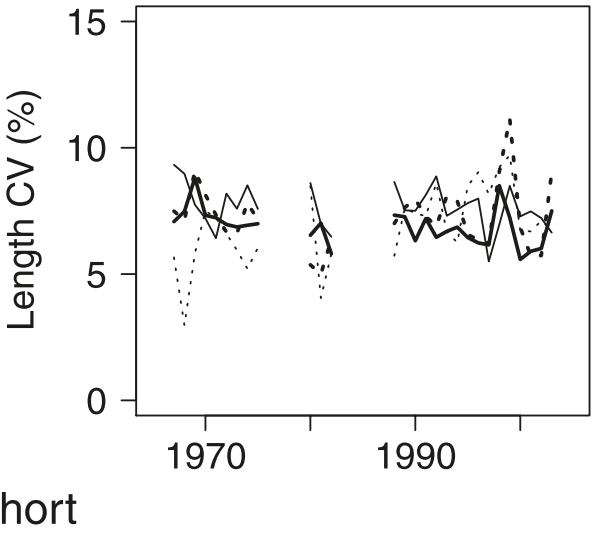

of individuals. We first show the proportion of total emigrants from each cohort that appear in the trap at a specific age (Figs. $2 a$ and $2 b$ ). We note that to calculate the proportion of the total emigrants from a given cohort departing at a specific age, we must have data for all four years in which members of that cohort might have emigrated. For the 1976-1979 and 1982-1987 cohorts, data for key ages are unavailable or unreliable.

From these plots, we see that over the four decades of the survey, the proportion of the cohort emigrating aged 1.5 to 2 remains about constant, whereas the proportion emigrating aged 2 to 2.5 increases from around $20 \%$ to between $40 \%$ and $50 \%$, with concomitant decreases in the proportion emigrating later in life. Interestingly, although the mean length of emigrants from a given cohort clearly increases with age, the mean length of emigrants of a given age shows no decadal trend (Fig. 2c), a characteristic shared with the length variability (Fig. 2d).

For much of the survey period, FRS-FL staff also carried out a late-summer electrofishing campaign in the Girnock during which representative reaches were multiple-pass fished, with all fish caught being counted, all parr and a sample of fry measured for fork length, and all parr scaled for age determination before release. Densities were estimated at each site by depletion calculations. For the period
1998-2000, this programme was expanded to monthly visits to a single station with individuals marked to allow their specific growth and survival to be monitored. Since 2000, a roughly bimonthly programme of electrofishing surveys has been executed covering a more representative sample of habitats within the burn.

Although the continuing programme of electrofishing did not cover the entire burn, the local abundance estimates that it produces can be extrapolated (see Buck and Hay 1984) to infer the total population of different cohorts. This process produces whole-burn population estimates, with year-to-year relativities that are probably reliable but absolute values that are sufficiently uncertain for it to be imprudent to attempt to make age-dependent parr survival a key element in our model, as we would then require a level of self-consistency between the electrofishing population estimates and the trap counts, which experience has shown us to be seldom practical.

Statistical investigations of local growth and survival of fry from recent cohorts (J. Thorley, FRS-FL, Pitlochry PH165LB, Scotland, unpublished data) have suggested that local fry density significantly affects growth and survival in the period leading up to the late-summer survey. We show fry abundances (Fig. 3) derived from the long-term, latesummer electrofishing data by methods described in Buck 
Fig. 3. Historical stock-fry relationship. This figure shows total fry numbers (circles) in the Girnock Burn above the smolt trap, estimated from electrofishing surveys, against total numbers of female spawners (grilse plus multi-sea-winter females). Points from the period 2000-2003, when eggs were stripped from the returning females and "planted out", are shown by squares. The line shows the relation defined in eq. A11, with $F_{0}=8862, F_{\max }=29212$, and $A_{\mathrm{h}}=24$, which yields $R^{2}=0.61$ for the nonplanted-out points compared with 0.45 for a two-parameter linear regression.

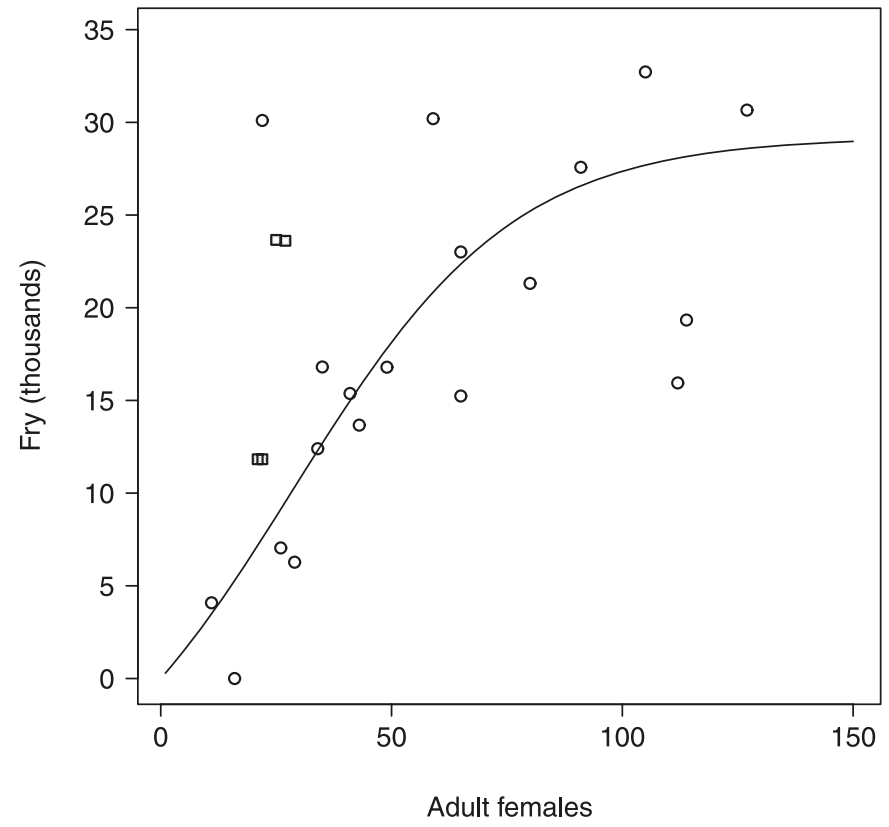

and Hay (1984) against spawner numbers. This plot illustrates a stock-recruitment relationship between late-summer fry densities and spawner numbers, the saturating form of which must arise from the complex of density-dependent effects that may occur between adult return to the river and observation of fry in the following year's survey.

Temperature loggers have been deployed for varying durations at various locations in the Girnock during the period of interest. However, only the one at Littlemill has been deployed continuously for the entire period. We show time series (Fig. 4) of the monthly averaged temperatures for four months typical of winter, spring, summer, and autumn (January, April, July, and October), together with regressions against year. We see that although autumn and winter temperatures have decreased by $0.76{ }^{\circ} \mathrm{C}$ and $0.57{ }^{\circ} \mathrm{C}$, respectively, between 1970 and 2000, spring and summer temperatures have increased by $1.46{ }^{\circ} \mathrm{C}$ and $1.04{ }^{\circ} \mathrm{C}$, respectively, over the same period.

\section{Materials and methods}

\section{The model}

The model used in this paper is an input-output description of the connection between individuals returning to a subcatchment to spawn and the subsequent emigration of their offspring. The stochastic description of growth around which this model is built is an extension of that used by Gurney et al. (2007) to model the growth of trout and salmon parr. To this growth description (extended to encom- pass growth of fry after emergence from the gravel) are added descriptions of the deposition of ova and their survival to become fry and emigration of parr to become smolts.

We give an extended mathematical description of this model in Appendix A. In this section, we set out the key properties of the underlying description of growth, discuss the extensions that transform it into a riverine input-output model, and define the parameters that will be used in subsequent discussion.

The model developed by Gurney et al. (2007) describes the dynamics of the length distribution of a cohort of functionally identical individuals growing in a stochastic environment in such a way that mean length at age increases towards an asymptotic value $L_{\infty}$ according to a von Bertalanffy (1938) pattern. The model's computational efficiency results from a formal description in terms of a development index $(q)$ related to individual length $(L)$ in such a way that a series of equal width classes represents the growth increment achieved by their occupants in a fixed time period (eq. A4).

The cohort description is updated at intervals proportional to the development index class width, $d q$ (eq. A13). Growth stochasticity is incorporated by assuming that in any update interval, an individual either grows enough to put it into the adjacent class (with probability $p$ ) or stays the same length (probability $1-p$ ). Gurney et al. (2007) showed that mean length at age then follows a von Bertalanffy pattern with realised growth rate $\gamma$ given by eq. A6.

To model growth seasonality, Gurney et al. (2007) assumed that $p$ had a high value (which we denote by $P$ ) between days (of the year) $D_{\mathrm{g}}$ and $D_{\mathrm{w}}$, whereas for the rest of the year, it is lower by a factor $\omega$. We carry over these assumptions for parr but recognise that fry occupy different habitat from parr and have a longer growing season (J. Thorley, FRS-FL, Pitlochry, PH16 5LB, Scotland, unpublished data). We assume that the summer growth rate for fry differs from that of parr by a factor $\varphi$ and that their growing season ends on day (of the year) $D_{\mathrm{w}}^{\mathrm{f}}$.

Gurney et al. (2007) assumed both growth probabilities and realised growth rate to be constant within a season. However, we seek to model temperature effects, so we need to write $\gamma$ as a function of temperature. Although salmon parr growth rates are known to fall at temperatures in excess of $18{ }^{\circ} \mathrm{C}$ (Elliott and Hurley 1997), Girnock temperatures seldom exceed this value (see Fig. 4). We represent $\gamma$ for both fry and parr by an activated process (eq. A8), with an activation temperature $\left(T_{\mu}\right)$ driven by temperatures linearly interpolated from the monthly average temperatures at Littlemill. For parr, we assume that the realised growth rate changes by the same factor as the growth probability at the summer-winter boundaries, so we write the scale for the activated process as $\gamma_{0}$ in summer and $\omega \gamma_{0}$ in winter. For fry, unpublished work on the raw data that underlies that used in this study (J. Thorley, FRS-FL, Pitlochry, PH16 5LB, Scotland, unpublished data) has shown significant density dependence of realised growth rate. Hence, for fry, we assume that very small cohorts have realised growth rate scale $\eta \gamma_{0}$, but that the scale drops linearly (with slope $\xi$ ) as numbers rise.

Two further extensions to the Gurney et al. (2007) struc- 
Fig. 4. Monthly average temperatures at Littlemill on the Girnock Burn from 1966 to 2005. Points joined by lines show monthly averaged temperatures $\left({ }^{\circ} \mathrm{C}\right)$. The solid straight line shows a linear regression of month temperature against year: $(a)$ January, $(b)$ April, $(c)$ July, and (d) October.

(a)

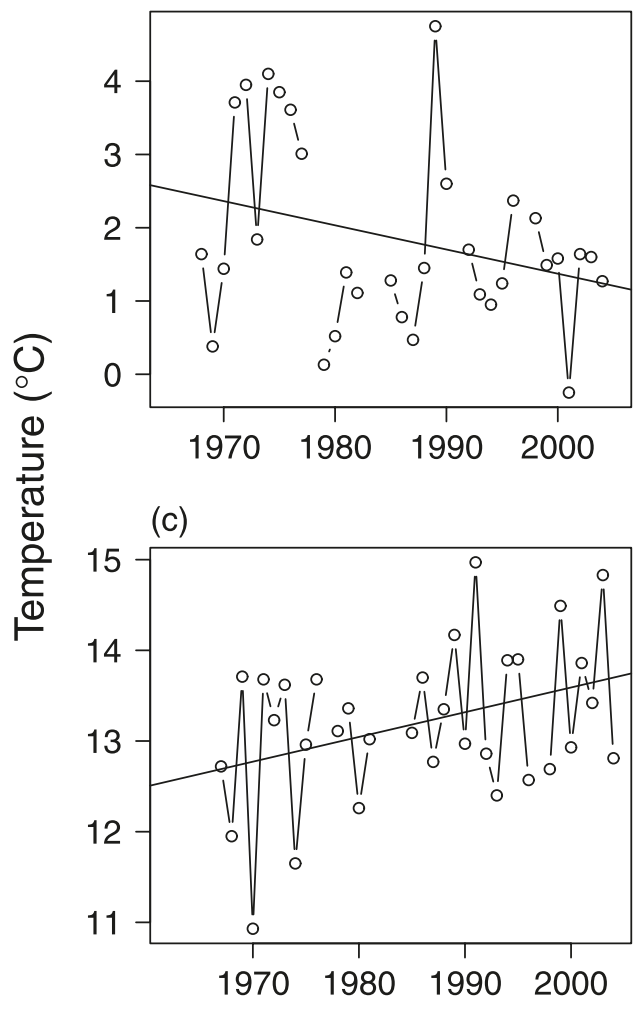

(b)

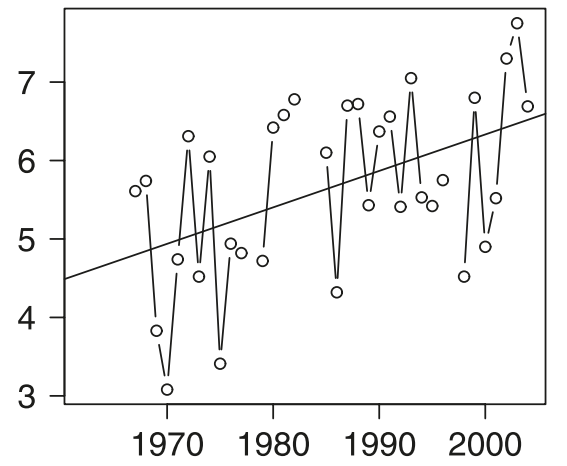

(d)

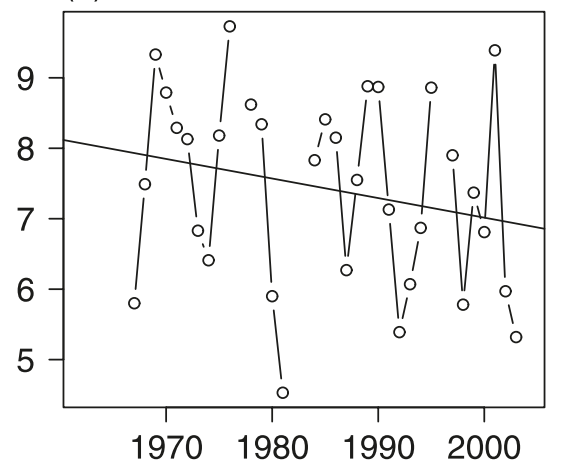

Year

ture are needed to construct the input-output model that we require for this study, namely, recruitment and emigration. To model emigration, we assume that the spring and autumn runs occur instantaneously on days (of the year) $D_{\mathrm{r}}^{\mathrm{spr}}$ and $D_{\mathrm{r}}^{\text {aut }}$, respectively. On these days, we assume that there is a length-dependent probability of emigrating that is very low for lengths, well below respective thresholds $L_{\mathrm{h}}^{\mathrm{spr}}$ and $L_{\mathrm{h}}^{\text {aut }}$, rising to $\varepsilon^{\mathrm{spr}}$ or $\varepsilon^{\text {aut }}$, respectively, for lengths well above threshold, with the transition occurring over a length range $L_{\mathrm{h}}^{\mathrm{spr}}$ or $L_{\mathrm{h}}^{\text {aut }}$, respectively.

Very little field data are available that we could use to elucidate the part of the life cycle between ova deposition and appearance of the fry in the autumn fry survey. The stock-recruitment relation shown in Fig. 3 demonstrates strong density dependence of survival from ova to fry but gives no hint of the processes that underlie this effect. Hence we arrange for appropriate numbers of fry to arrive at the autumn survey (on day of the year $D_{\text {elf }}$ ) by depositing the numbers implied by the stock-recruitment relation (eq. A11) in the system at the time when the alevins are emerging from the gravel (which we denote by $D_{\text {hatch }}$ ) and making them immortal until $D_{\text {elf }}$. The newly emerged individuals are assumed to have mean length $L_{\text {hatch }}$ and length $\mathrm{CV} C_{\text {hatch }}$. This slightly convoluted strategy allows us to model density-dependent fry growth (at least approximately) while avoiding unverifiable detail in the description of fry mortality.

We give a complete list of model parameters, together with their interpretation and best-fit values (Table 1). We can obtain values for some of these parameters from independent data, the literature, or inspection of biological or operational reality. In the first class are the values shown in the caption for Fig. 3, obtained from the data shown in the figure using nonlinear minimization (the Nelder-Mead algorithm implemented in the $\mathrm{R}$ routine "optim") of the meansquare deviation of observed and predicted points. In the second are the asymptotic length $L_{\infty}$ (Gurney et al. 2007), the activation temperature $T_{\mu}$ (Elliott 1976), the parr mortality rate (Egglishaw and Shackley 1985), and the growing season limits (Gurney et al. 2007). In the third are the emigrant run timings, which were selected to represent the end of the spring and autumn periods during which emigrants leave the burn and the timing of the late-summer electrofishing campaign.

\section{Data fitting}

In the remainder of this paper, we use fits of the model to various subsets of the data both to evaluate parameters we cannot determine independently and to test the model's validity by examining the quality of the best achievable fit. In related work (Gurney et al. 2007), we used various brands of nonlinear minimization for this purpose and determined confidence limits by data resampling. Here we use the Markov chain Monte-Carlo approach to Bayesian inference to determine the full probability distribution for the vector of unknown parameters. For the data discussed here, this 
Table 1. Model parameters, units, best-fit values, and sources.

\begin{tabular}{|c|c|c|c|c|}
\hline Parameter & Value & Unit & Interpretation & Source \\
\hline \multicolumn{5}{|c|}{ Population representation } \\
\hline$d q$ & 0.01 & & Development index class width & Arbitrary \\
\hline$L_{\infty}$ & 200 & $\mathrm{~mm}$ & Asymptotic length in burn & Gurney et al. (2007) \\
\hline \multicolumn{5}{|c|}{ Fry recruitment } \\
\hline$F_{0}$ & 8862 & no. of fry & Stock-recruitment - offset & Fig. 3 fit \\
\hline$F_{\max }$ & 29212 & no. of fry & Stock-recruitment - maximum & Fig. 3 fit \\
\hline$A_{\mathrm{h}}$ & 24 & no. of females & Stock-recruitment - half saturation & Fig. 3 fit \\
\hline$D_{\text {hatch }}$ & 90 & day (of year) & Hatch day & Youngson et al. (2004) \\
\hline$L_{\text {hatch }}$ & 18 & $\mathrm{~mm}$ & Mean length at hatch & Youngson et al. (2004) \\
\hline$C_{\text {hatch }}$ & 3 & $\%$ & Length $\mathrm{CV}$ at hatch & Youngson et al. (2004) \\
\hline \multicolumn{5}{|c|}{ Parr growth and mortality } \\
\hline$D_{\mathrm{g}}$ & 72 & day (of year) & Growing season - start & Gurney et al. (2007) \\
\hline$\gamma_{0}$ & 0.091 & $\% \cdot$ day $^{-1}$ & Realized growth rate scale & Fitted - Table 3 \\
\hline$T_{\mu}$ & 11.9 & ${ }^{\circ} \mathrm{C}$ & Activation temperature & Elliott (1976) and Table 3 \\
\hline$P$ & 0.069 & & Summer growth probability & Fitted - Table 3 \\
\hline$\omega$ & 0.237 & & Winter-summer growth probability & Fitted - Table 3 \\
\hline$D_{\mathrm{w}}$ & 188 & day (of year) & Growing season - end & Gurney et al. (2007) \\
\hline$m$ & 0.19 & $\% \cdot$ day $^{-1}$ & Per capita mortality rate & Egglishaw and Shackley (1985) \\
\hline \multicolumn{5}{|c|}{ Fry growth } \\
\hline$\eta$ & 0.569 & & Fry-parr realised growth rate scale & Fitted - Table 3 \\
\hline$\varphi$ & 3.07 & & Fry-parr growth probability & Fitted - Table 3 \\
\hline$\xi$ & $3.98 \times 10^{-7}$ & day $^{-1} \cdot$ fry $^{-1}$ & Fry growth density dependence & Fitted - Table 3 \\
\hline$D_{\text {elf }}$ & 200 & day (of year) & Electrofishing survey & Nominal \\
\hline$D_{\mathrm{w}}^{\mathrm{f}}$ & 200 & day (of year) & Fry growing season — end & J. Thorley, unpublished \\
\hline \multicolumn{5}{|c|}{ Spring emigration } \\
\hline$D_{\mathrm{r}}^{\mathrm{spr}}$ & 120 & day (of year) & Run & Nominal \\
\hline$L_{\mathrm{h}}^{\mathrm{spr}}$ & 102 & $\mathrm{~mm}$ & Sigmoid probability function - centre & Fitted - Table 3 \\
\hline$L_{\mathrm{W}}$ & 0.104 & $\mathrm{~mm}$ & Sigmoid probability function — width & Fitted - Table 3 \\
\hline$\varepsilon^{\mathrm{spr}}$ & 1.0 & & $\operatorname{Pr}\{$ qualified individual emigrates $\}$ & Assumed \\
\hline \multicolumn{5}{|c|}{ Autumn emigration } \\
\hline$D_{\mathrm{r}}^{\text {aut }}$ & 300 & day (of year) & Run & Nominal \\
\hline$L_{\mathrm{h}}^{\text {aut }}$ & 95.6 & $\mathrm{~mm}$ & Sigmoid probability function - centre & Fitted - Table 3 \\
\hline$\varepsilon^{\text {aut }}$ & 0.29 & & $\operatorname{Pr}\{$ qualified individual emigrates $\}$ & Fitted - Table 3 \\
\hline
\end{tabular}

approach has produced fits comparable with those obtained by nonlinear minimization, together with full information on parameter uncertainties and correlations, at a computational cost very similar to that for a single nonlinear minimization.

Because the computational efficiency of the model evaluation is the key to producing Markov chains of useful length, we use a self-programmed implementation of the Metropolis-Hastings algorithm (Hastings 1970), written in a compiled language (Pascal), in preference to a prewritten application in an interpreted language such as R. Our approach is based on a likelihood function closely related to the error function used in our earlier work. For each point, we calculate a relative absolute error defined as the absolute difference between observation and prediction divided by the $95 \%$ confidence range for the observed value. For each curve, we calculate the mean relative absolute error per point. Finally, we calculate the mean of the four curve errors and then determine the likelihood of the observations assuming that the relative absolute error follows a standard Laplace distribution. This formulation, which is equivalent to assuming that the $N$ data points are individually Laplace distributed and using the $N$ th root of the probability as our likelihood function, enables us to avoid generating computationally unfeasible likelihoods, even from very noisy data.

In almost every case, we know virtually nothing about either the expectation value or the distribution of the unknown parameters, so we employ a prior distribution that expresses very generalized initial knowledge - all parameters must be nonnegative and probabilities must lie in $[0,1]$. The proposal distribution echoes the Laplace form of the assumed error distribution, but with a standard deviation for each component chosen to be a standard fraction of a scale vector, normally set equal to the initial parameter values.

During an initial burn-in period (10000 evaluations for single cohort fits, 1000 for time series fits involving 36 cohorts), the scales are varied so that $50 \%$ to $70 \%$ of proposed points are accepted, thus resulting in efficient exploration of the posterior distribution. After completion of the burn-in period and finalization of the proposal distribution, a series of evaluations (100000 for single cohort fits, 20000 for time series fits) is used to construct the definitive Markov chain. During this process, we record the likelihood associated with each proposed point and use the parameter vector 
Fig. 5. Best fit to 2001 cohort date. Frame (a) shows predicted (solid line) and observed (points) mean length at age. Error bars show $95 \%$ confidence range calculated by bootstrap resampling. Frame $(b)$ shows predicted (solid line) and observed (points) CV of length at age. Error bars show 95\% confidence range calculated by bootstrap resampling. Frame $(c)$ shows predicted (points joined by lines) and observed (points with error bars) proportion of emigrants per run. Error bars are calculated assuming that emigration is a binomial process with small success probability, so the variance of numbers observed is equal to the mean. Frame $(d)$ shows predicted (points joined by lines) and observed (points with error bars) mean length of emigrants in each run. Error bars are calculated assuming that the observations are normally distributed around the mean.

(a)

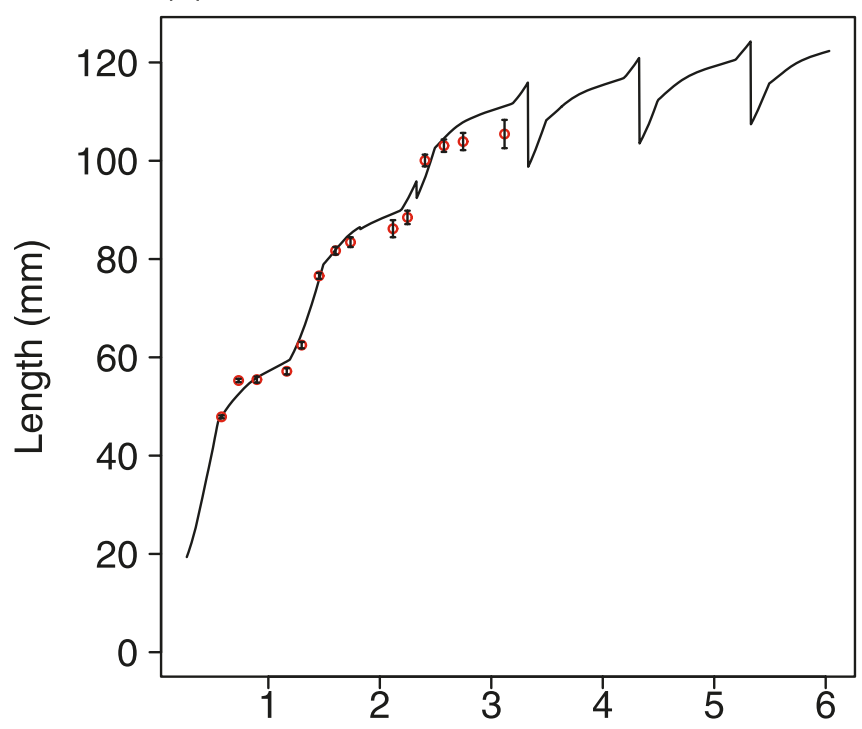

(c)

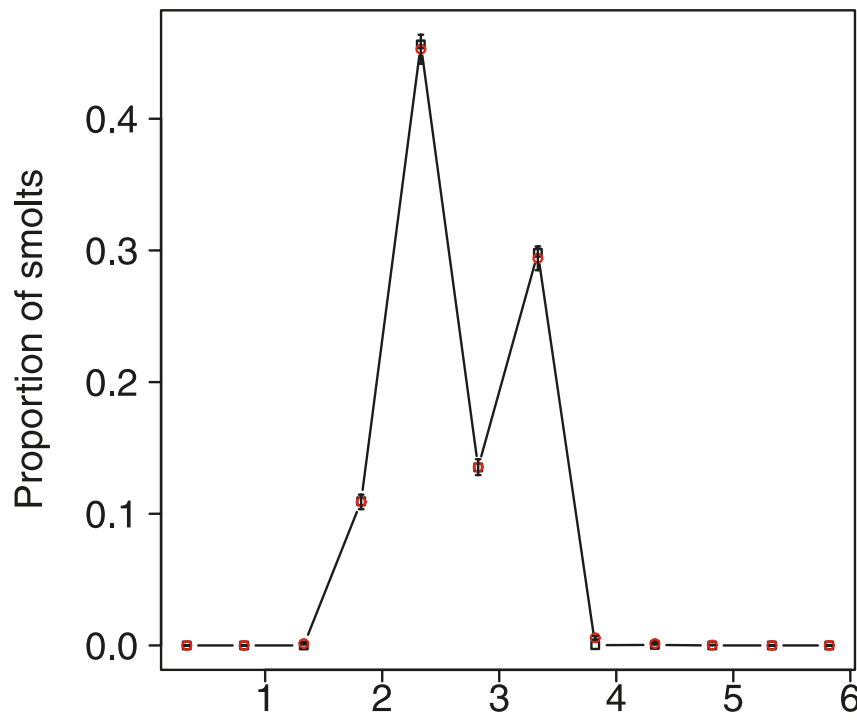

(b)

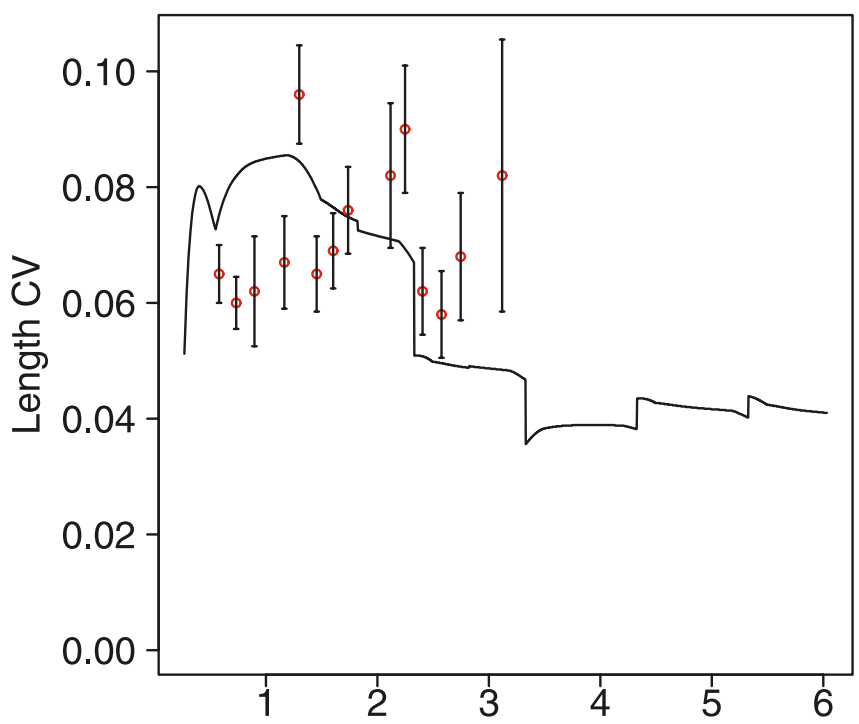

(d)

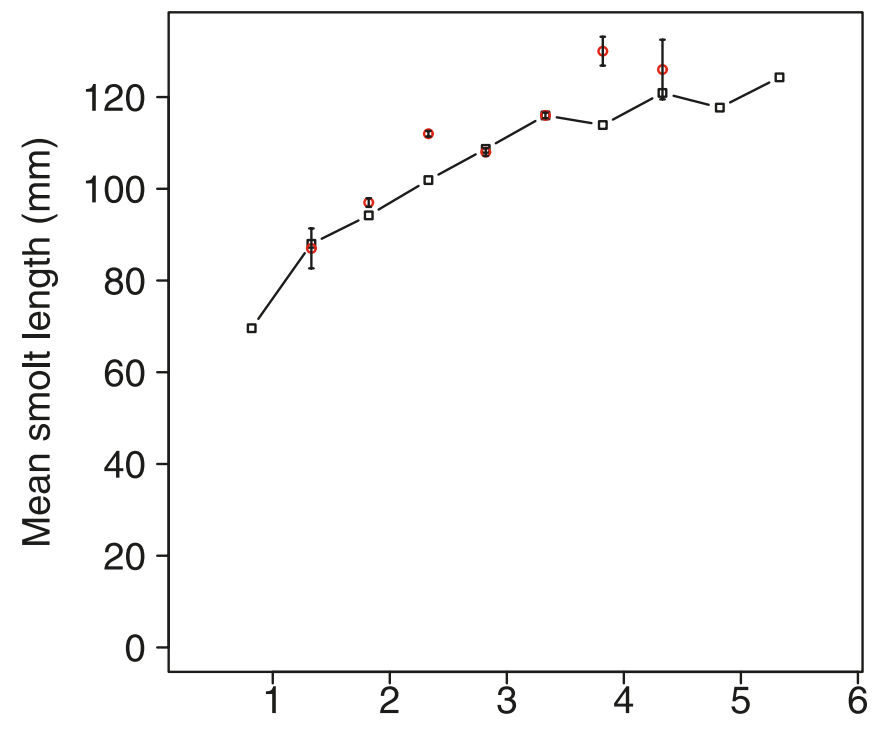

Age (years from 1 January)

with maximum likelihood as our best fit. Although we did not use any formal test for convergence of the Markov chain, multiple applications of this process in test cases demonstrated that the results are robust.

\section{Results}

Fitting to the 1997-2003 high-resolution growth data

Our first fitting exercise uses high temporal resolution data for cohorts hatched in the years 1997 to 2003 to test model validity and estimate all but one of the parameters in Table 1 for which we do not have independent values. During the latter half of the period for which such data are available, ova planting may have perturbed the fry stockrecruitment relation and (or) the parr mortality rate. The mean and $\mathrm{CV}$ of size at age and the mean emigrant length are weakly dependent on mortality and recruitment. Although the numbers emigrating at age are strongly af- 
Fig. 6. Best fit to 2003 cohort data. Frame (a) shows predicted (solid line) and observed (points) mean length at age. Error bars show $95 \%$ confidence range calculated by bootstrap resampling. Frame $(b)$ shows predicted (solid line) and observed (points) CV of length at age. Error bars show $95 \%$ confidence range calculated by bootstrap resampling. Frame $(c)$ shows predicted (points joined by lines) and observed (points with error bars) proportion of emigrants per run. Error bars are calculated as in Fig. 5. Frame $(d)$ shows predicted (points joined by lines) and observed (points with error bars) average length of emigrants in each run. Error bars are calculated as in Fig. 5.

(a)

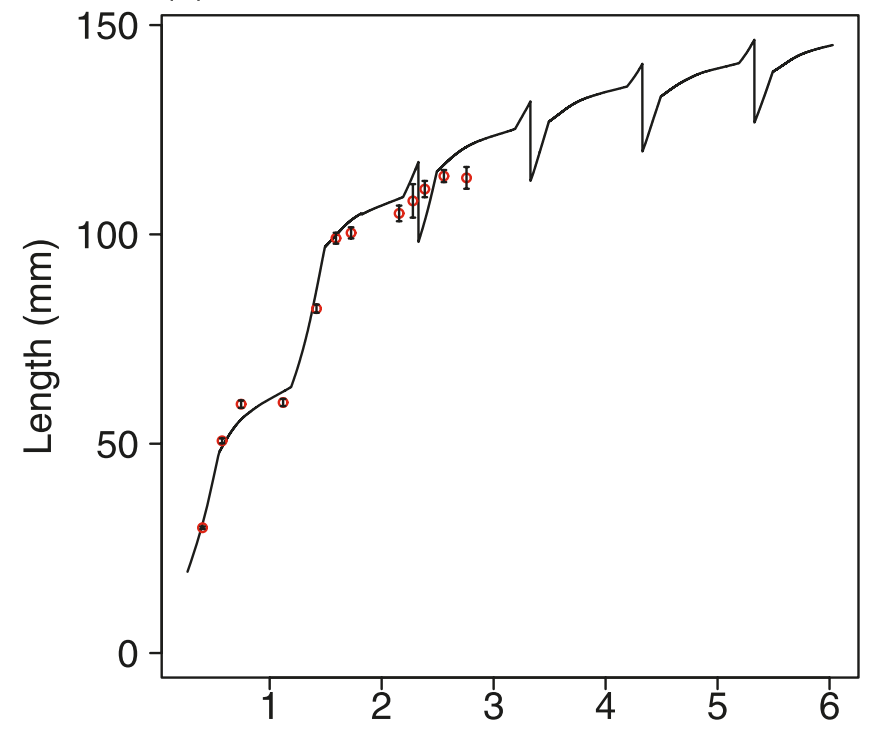

(c)

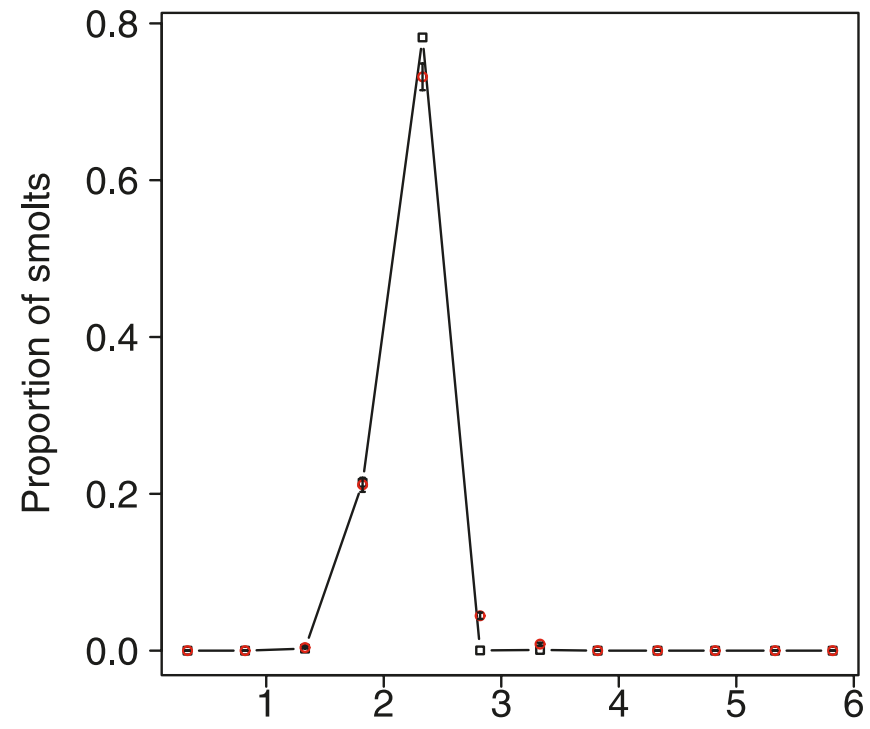

(b)

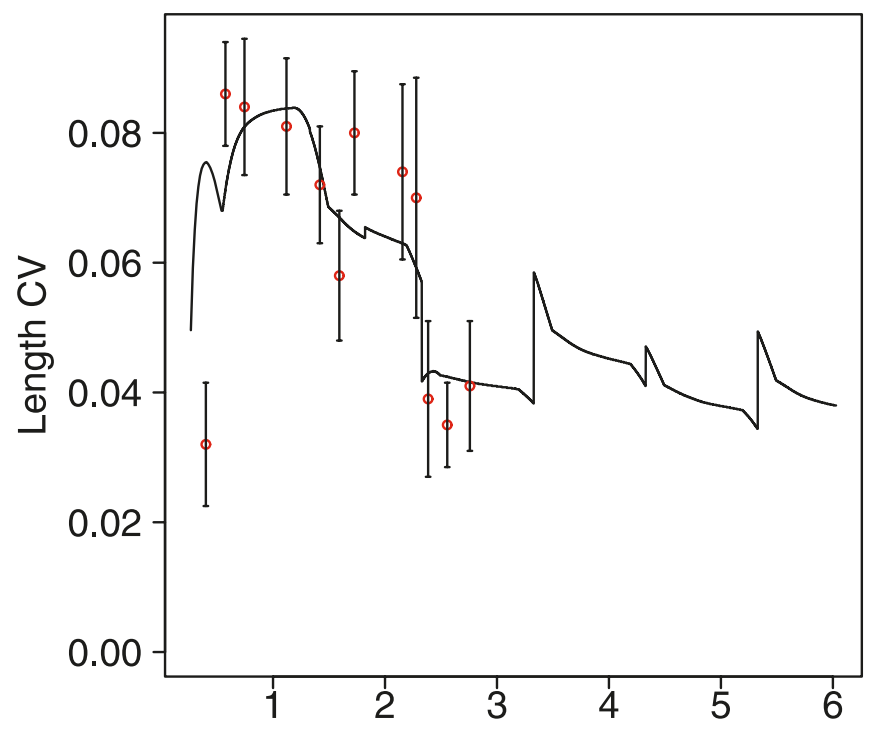

(d)

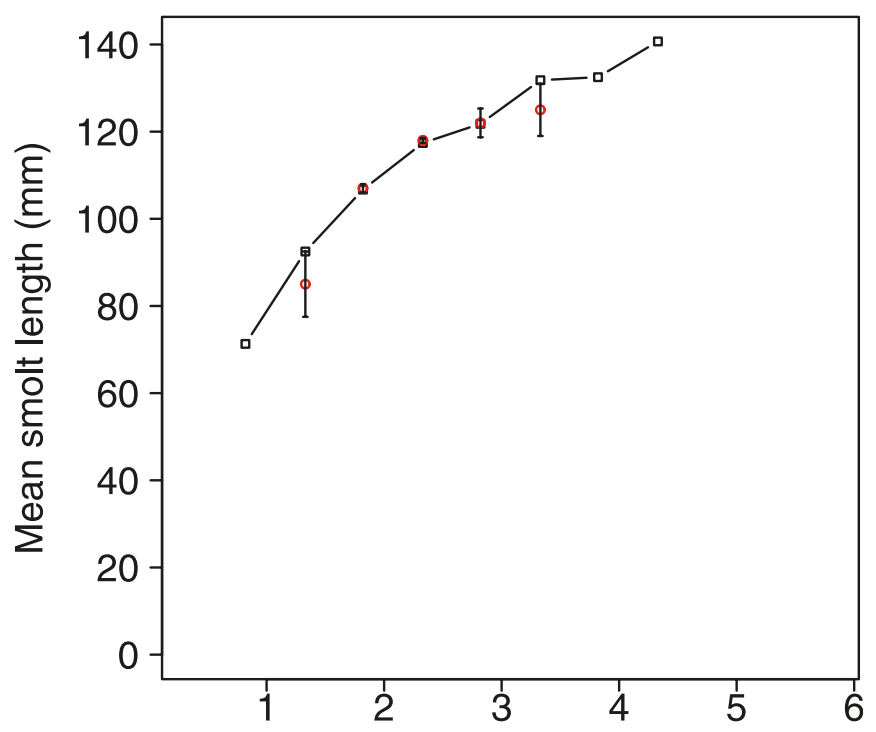

\section{Age (years from 1 January)}

fected by both these factors, the proportions departing at given ages are not. Hence, we minimize the effect of using data from cohorts observed during a period of river manipulation by fitting the mean and $\mathrm{CV}$ of size at age, the proportion of emigrants in each run, and the mean length of these groups of emigrants - all of which are almost independent of both the stock-recruitment relation and the parr mortality rate.

To investigate the possibility that unmodelled year-to-year changes in the physical and biotic environment are a signifi- cant source of year-to-year variability, we fit the model separately to each of the observed cohorts. In such fits, the fry growth rate density-dependence parameter $(\xi)$ is almost completely confounded with the fry-to-parr growth rate scale ratio $(\eta)$, so we set $\xi=0$.

For all fitted cohorts, the quality of fit closely resembles those illustrated in Figs. 5 and 6. The mean length-at-age data are well fitted, as are the proportions emigrating at age, despite considerable year-to-year variation in the temporal distribution of emigration (compare Fig. $5 c$ and 
Table 2. Individual cohort fits from 1997 to 2003 , calculated with the activation temperature $T_{\mu}=12{ }^{\circ} \mathrm{C}$ ) and no density dependence in fry growth $(\xi=0)$.

\begin{tabular}{llllllll}
\hline Parameter & 1997 & 1998 & 1999 & 2000 & 2001 & 2002 & 2003 \\
\hline$\gamma_{0}$ & 0.070 & 0.102 & 0.067 & 0.096 & 0.064 & 0.111 & 0.122 \\
& $(0.07,0.17)$ & $(0.05,0.14)$ & $(0.04,0.08)$ & $(0.07,0.12)$ & $(0.05,0.08)$ & $(0.09,0.12)$ & $(0.07,0.12)$ \\
$P$ & 0.016 & 0.020 & 0.153 & 0.089 & 0.149 & 0.579 & 0.049 \\
& $(0.01,0.07)$ & $(0.01,0.06)$ & $(0.02,0.45)$ & $(0.01,0.14)$ & $(0.06,0.56)$ & $(0.28,0.83)$ & $(0.02,0.11)$ \\
$\omega$ & 0.591 & 0.230 & 0.445 & 0.142 & 0.315 & 0.108 & 0.216 \\
& $(0.02,0.60)$ & $(0.04,0.93)$ & $(0.28,0.96)$ & $(0.02,0.30)$ & $(0.19,0.59)$ & $(0.07,0.25)$ & $(0.20,0.53)$ \\
$\eta$ & 0.147 & 0.611 & 1.158 & 0.793 & 1.065 & 0.551 & 0.539 \\
& $(0.08,0.37)$ & $(0.36,1.21)$ & $(0.94,2.34)$ & $(0.56,1.20)$ & $(0.93,1.54)$ & $(0.44,0.71)$ & $(0.49,0.92)$ \\
$\varphi$ & 0.445 & 23.94 & 5.24 & 6.36 & 4.83 & 1.38 & 15.5 \\
& $(0.15,4.89)$ & $(1.95,24.3)$ & $(0.70,26.4)$ & $(4.26,12.3)$ & $(0.28,12.4)$ & $(0.32,1.55)$ & $(3.91,27.7)$ \\
$L_{\mathrm{h}}^{\text {spr }}$ & 106 & 110 & 102 & 98 & 98 & 104 & 96 \\
& $(103,107)$ & $(108,115)$ & $(100,108)$ & $(97,101)$ & $(97,101)$ & $(102,106)$ & $(96,106)$ \\
$L_{\mathrm{w}}$ & 0.026 & 0.65 & 0.20 & 0.04 & 1.36 & 0.62 & 1.67 \\
& $(0.03,0.88)$ & $(0.19,3.13)$ & $(0.03,0.67)$ & $(0.02,0.06)$ & $(1.59,4.10)$ & $(0.13,1.31)$ & $(0.82,3.42)$ \\
$L_{\mathrm{h}}^{\text {aut }}$ & 91.5 & 101 & 98.9 & 98.2 & 91.4 & 93.4 & 97.2 \\
& $(87,94)$ & $(98,109)$ & $(93,103)$ & $(97,101)$ & $(91,99)$ & $(90,95)$ & $(97,109)$ \\
$\varepsilon^{\text {aut }}$ & 0.20 & 0.34 & 0.29 & 0.40 & 0.24 & 0.31 & 0.19 \\
& $(0.15,0.32)$ & $(0.21,0.46)$ & $(0.12,0.33)$ & $(0.29,0.47)$ & $(0.22,0.35)$ & $(0.21,0.38)$ & $(0.18,0.64)$ \\
\hline
\end{tabular}

Note: Best-fit values are given on the first line, with 5 and 95 percentile values in parentheses below. Units as in Table 1.

Table 3. Best-fit values for all fitted parameters.

\begin{tabular}{|c|c|c|c|c|c|c|}
\hline \multirow[b]{2}{*}{ Parameter } & \multirow[b]{2}{*}{ Interpretation } & \multirow[b]{2}{*}{ Unit } & \multirow[b]{2}{*}{$\begin{array}{l}\text { Cohort weighted } \\
\text { average }\end{array}$} & \multicolumn{3}{|c|}{ Time series, 1967-2003 } \\
\hline & & & & 5 percentile & Best fit & $\begin{array}{l}95 \\
\text { percentile }\end{array}$ \\
\hline$\overline{T_{\mu}}$ & Activation temperature & ${ }^{\circ} \mathrm{C}$ & {$[12.0]$} & 7.7 & 11.9 & 14.6 \\
\hline$\gamma_{0}$ & Realised growth rate scale & $\% \cdot$ day $^{-1}$ & 0.090 & 0.061 & 0.091 & 0.102 \\
\hline$P$ & Parr summer growth rate probability & & 0.058 & 0.026 & 0.069 & 0.155 \\
\hline$\omega$ & Winter-summer growth rate probability & & 0.237 & & {$[0.237]$} & \\
\hline$\eta$ & Fry-parr realised growth rate scale & & 0.569 & & {$[0.569]$} & \\
\hline$\varphi$ & Fry-parr growth probability & & 3.07 & & 3.07 & \\
\hline$L_{\mathrm{h}}^{\mathrm{spr}}$ & Spring smolt probability centre & $\mathrm{mm}$ & 102 & & {$[102]$} & \\
\hline$L_{\mathrm{w}}$ & Smolt probability width & $\mathrm{mm}$ & 0.104 & & {$[0.104]$} & \\
\hline$L_{\mathrm{h}}^{\text {aut }}$ & Autumn smolt probability centre & $\mathrm{mm}$ & 95.6 & 90.5 & 92.5 & 96.9 \\
\hline$\varepsilon^{\text {aut }}$ & $\operatorname{Pr}\{$ qualified emigrates $\}-$ autumn & & 0.29 & & {$[0.29]$} & \\
\hline$\xi$ & Fry growth rate scale density dependence & $\% \cdot$ day $^{-1} \cdot$ fry $^{-1}$ & {$[0.0]$} & $2.8 \times 10^{-8}$ & $3.98 \times 10^{-7}$ & $4.1 \times 10^{-7}$ \\
\hline
\end{tabular}

Note: Column four shows weighted averages of the cohort-by-cohort fitted values from the 1997-2003 data. Column six shows best-fit values for a subset of parameters refitted ot the time series input-output data from 1967-2003. The 5 and 95 percentiles for these refitted parameters are given in columns five and seven, respectively. Quantities in columns 4 and 6 shown in brackets were taken as constant for the fitting exercise concerned.

Fig. 6c). The mean smolt length data are also well fitted, with the exception of points generated by very small numbers of fish at the start and end of the sequence of emigration opportunities. The model's performance in mimicking the observed $\mathrm{CV}$ of length at age is more mixed. In the case of the 2003 cohort, the match between predictions and data is broadly good. However, for the 2001 cohort, there is an initial sequence of rising $\mathrm{CV}$ with age, which the model struggles to reproduce.

The best-fit values for each cohort and the 5 and 95 percentiles are shown (Table 2). Examination of the Markov chains from the estimation process shows that most parameter estimates are only weakly correlated with others in the parameter vector, the only exception being the realised growth rate scale $\gamma_{0}$, which is negatively correlated with the winter-to-summer growth rate scale ratio, $\omega$ (see
Appendix B). This correlation occurs because low winter and high summer growth rates produce the same yearly growth increment as higher winter and lower summer growth rates. It is particularly evident where the data do not define the summer-winter growth difference precisely.

We show a canonical parameter set (Table 3) constructed as a weighted average over cohorts with weights inversely proportional to the range between the 5 and 95 percentiles. Comparing this canonical parameter set (Table 3, column 4) with the best-fit parameters (Table 2) reveals some robust patterns.

Parr realised growth rate scales $\left(\gamma_{0}\right)$ for individual cohorts are consistent with the canonical average value of $0.09 \% \cdot$ day $^{-1}$, except for 1999 and 2001, which show significantly lowered values. Individual-to-individual variability in parr growth is generally high, as indicated by a canonical 
Fig. 7. Best fit to long-run time series. (a) Predictions (bold broken line) and observation (circles) of the proportion of all emigrants from cohorts from 1967 to 2003 leaving in the autumn of the year in which they have river age 1, together with predictions (bold solid line) and observations (squares) of the proportion leaving the following spring. (b) Predictions and observations, similarly distinguished, for the proportions emigrating in the autumn of the year in which they have river age 2 and the following spring. (c) Predictions and observations for the mean length of the subcohorts portrayed in $a$. $(d)$ The mean length for the subcohorts portrayed in $b$.

(a)

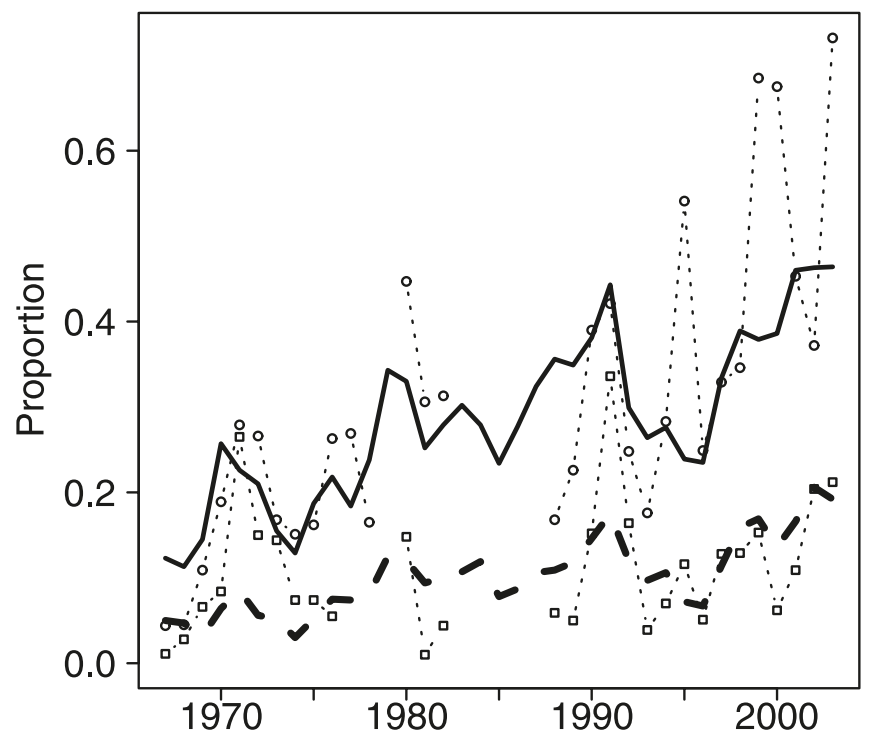

(c)

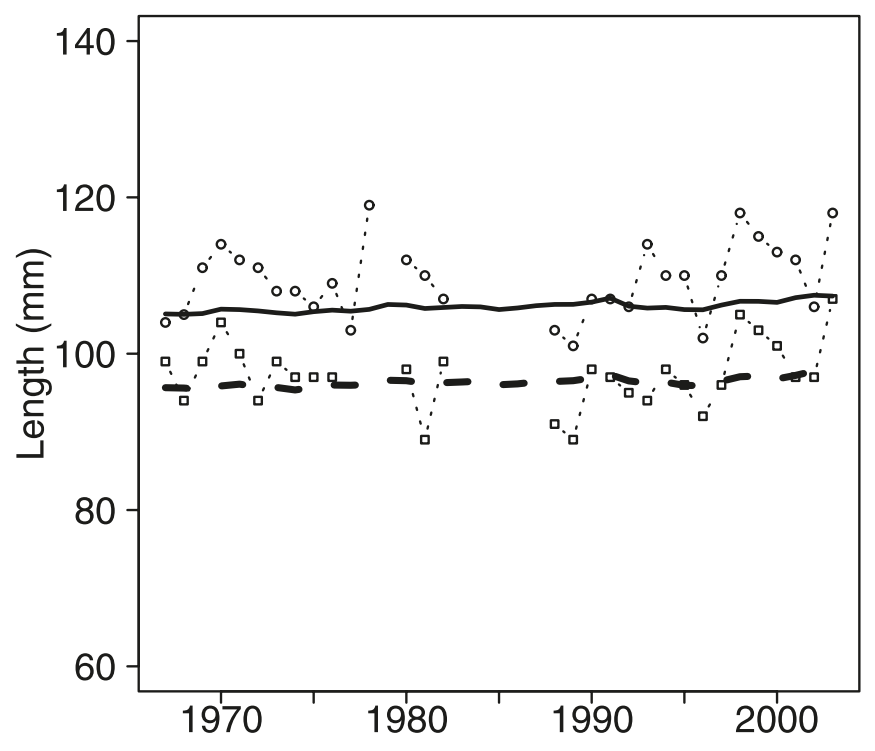

(b)

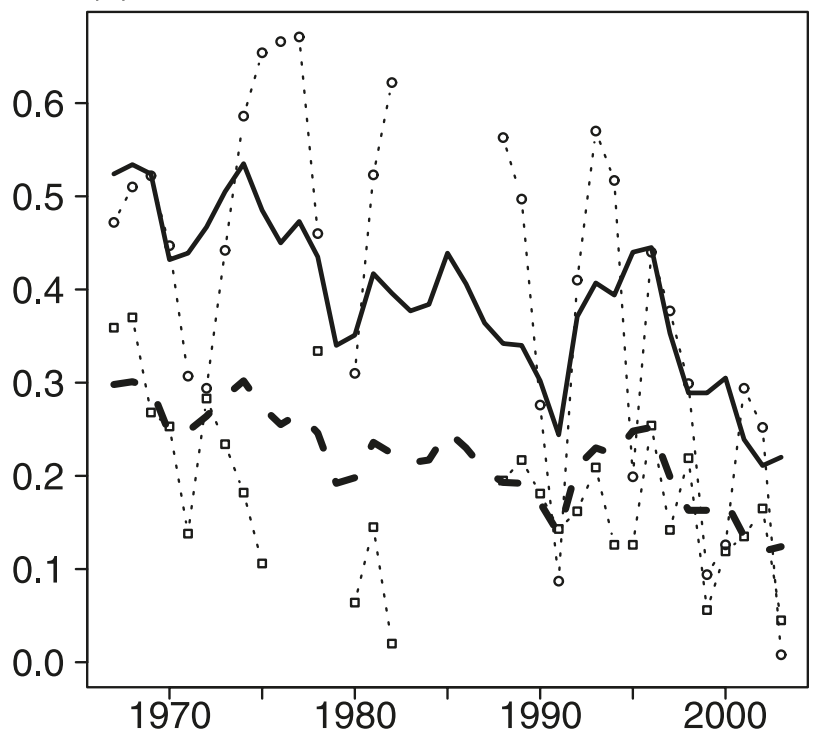

(d)

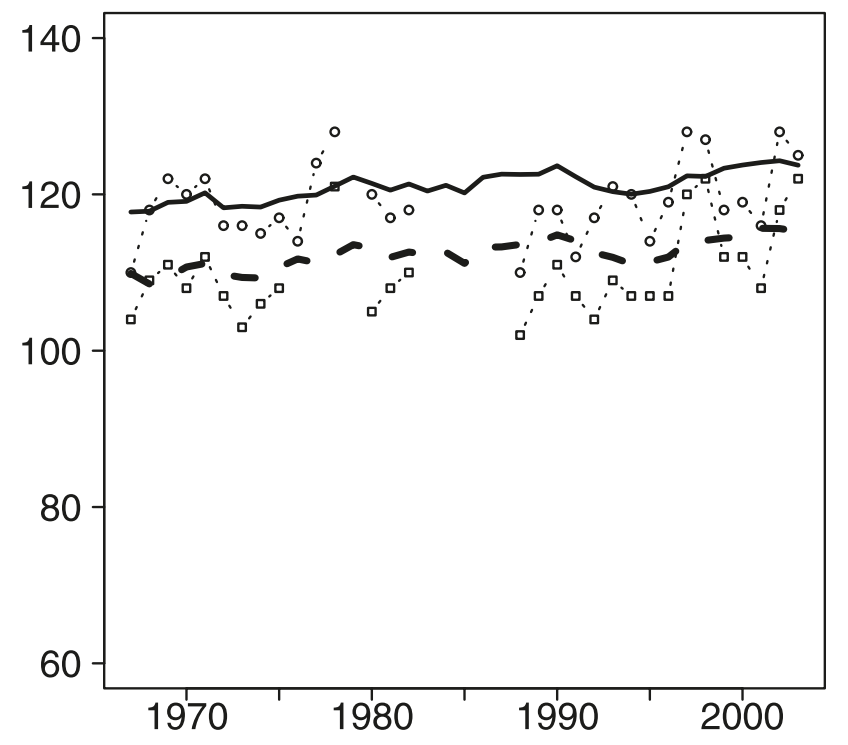

Cohort

value of $P=0.058$, the exception being 2002, with a 5 percentile $P$ value of 0.28 .

The step-like character of the mean length at age curves and the depression of winter growth below the level that temperature alone would imply are reflected in the ratio of winter to summer growth rate scales. These are broadly consistent with a canonical value of $\omega=0.237$, the only exception being 1999, with a 5 percentile value of 0.28 .
Estimates of the ratio of the realised growth rate scales of fry and parr $(\eta)$ vary significantly between cohorts. The weighted average value over all cohorts is 0.569 , but only three of the seven individual estimates are consistent with this value, with two of the remainder being higher and two lower. However, only two cohorts have $\eta>1$, and even then the confidence limits encompass unity. We conclude that fry growth is generally slightly slower than that for parr. 
Fig. 8. Postdicting total emigrant production. Lines show predicted total emigrants per cohort. Solid circles show observed total emigrants per cohort. (a) The solid line shows predicted emigrants per cohort with parameters from Table 1 . The broken line shows predictions with cohorts from 2001 having a stock-recruitment half-saturation spawner population $A_{\mathrm{h}}=17$ for cohorts from 2001 onwards. The dotted line shows predictions with all cohorts from 2001 on having parr mortality rate $m=0.13 \% \cdot$ day $^{-1}$. (b) The solid line shows predictions with parameters in Table 1 except that cohorts from 2001 on have $A_{\mathrm{h}}=17$, driven by monthly average temperatures illustrated in Fig. 4 . The broken and dotted lines show an identical run except that all cohorts are subjected to temperatures from the equivalent period in 1969 (dotted line) or 2003 (broken line).

(a)

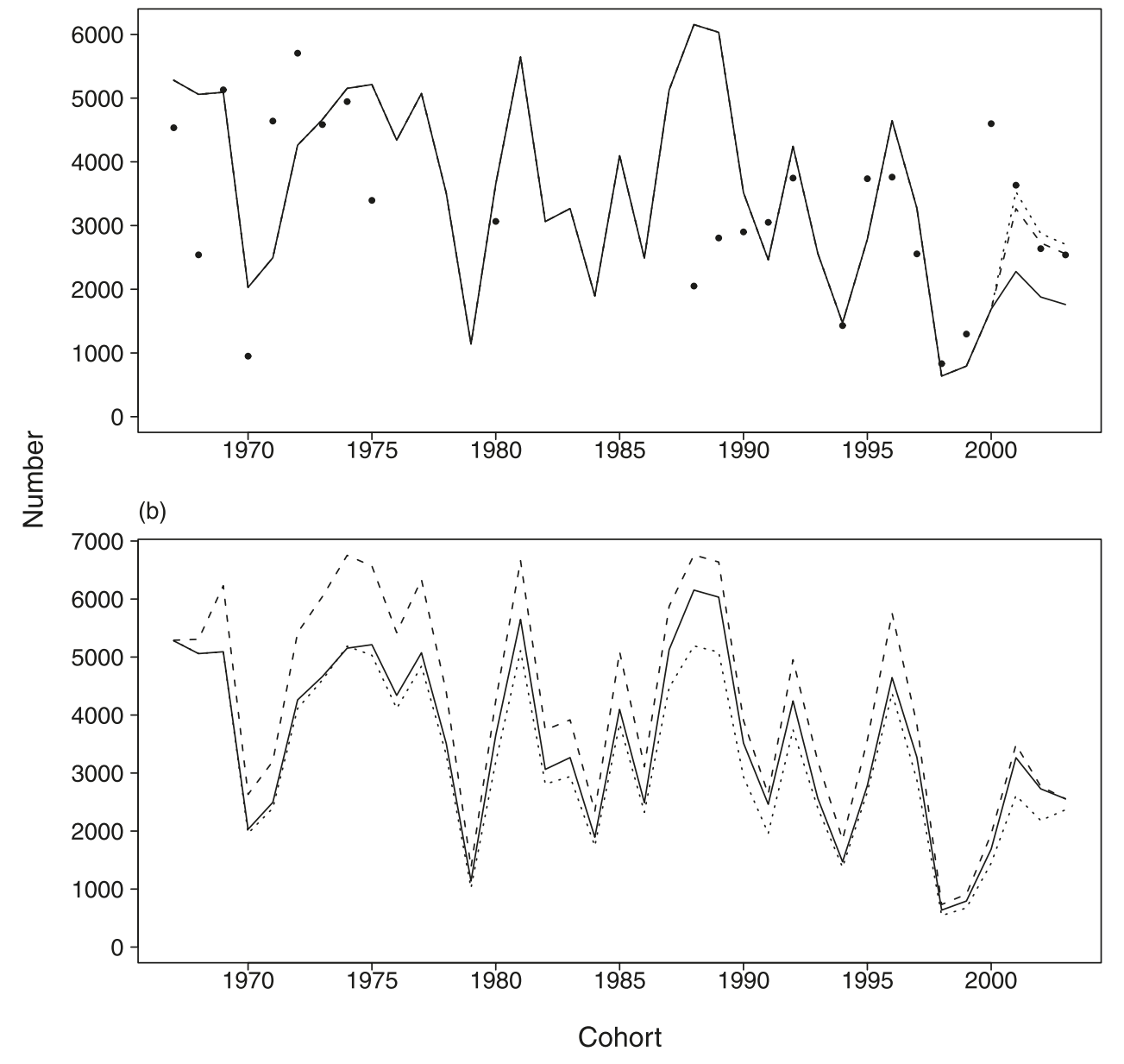

Individual-to-individual variability in fry growth is clearly less than that for parr, with all the individual cohort estimates for the growth probability ratio, $\varphi$, being consistent with the weighted average value of 3.07.

The estimated values for the spring emigration threshold, while individually well defined, show significant variation from year to year. Again three of the seven cohorts are consistent with a canonical value of $102 \mathrm{~mm}$, while two are clearly higher and two lower. All but one of the estimated values for autumn emigration thresholds are lower than the spring estimate for the same cohort, and again three cohorts are consistent with the weighted average value of $95.6 \mathrm{~mm}$, while two of the remainder are lower and two higher.

The estimates for the transition width $\left(L_{\mathrm{w}}\right)$, while varying considerably, are all small, with no best-fit value exceeding $2 \mathrm{~mm}$. The cohort estimates for the proportion of qualified autumn emigrants that actually leave are all consistent with a weighted average value of 0.29 .

\section{Fitting to the 1967-2003 time series}

The input-output data for the period 1967-2003 are sufficiently rich for the goodness of fit obtainable by optimizing a small group of unknown parameters against it to provide a valid test of our model. We first focus on trends in size and age at smolting, i.e., on the proportion of the total emigrants from a given cohort leaving in a given run, and the mean length of such groups of emigrants (Fig. 2).

Our fitting strategy will be to estimate the only parameter for which we so far have neither a literature-derived nor a fitted value (the fry density-dependence slope, $\xi$ ) together with the activation temperature $\left(T_{\mu}\right)$, the baseline growth rate scale $\left(\gamma_{0}\right)$, the baseline growth probability $(P)$, and the difference between the spring and autumn emigration thresholds.

Using the same MCMC approach as before, we produce a best fit (Fig. 7) that captures both the trend and the main features of the year-to-year variations in proportional emigration. There are some year-to-year variations that the model 
fails to capture, for example, periods of above-trend emigration in the spring of the year in which the cohort's river age is three years and concomitant below-trend emigration of the previous autumn. Experiments with model variants without fry growth density dependence (not shown) displayed observably larger deviations from historical behaviour.

Although the model fails to postdict much of the year-toyear variability in size at smolting, it correctly captures both the trend and the age relativities of this quantity - a property noticeably absent from fitting experiments (not shown) with versions of the model with the spring and autumn smolt characteristic length $\left(L_{\mathrm{h}}^{\mathrm{spr}}\right.$ and $\left.L_{\mathrm{h}}^{\mathrm{aut}}\right)$ set equal.

The best-fit parameters for the fit illustrated (Fig. 7) are given (Table 3, column six). From this we see that the bestfit value of $T_{\mu}$ is very close to the Elliott (1976) value of $12{ }^{\circ} \mathrm{C}$. Neither the parr summer growth rate scale $\left(\gamma_{0}\right)$ nor the growth probability $(P)$ differ significantly from the canonical (weighted average) values for the individual cohort fits (Table 3, column 4). Although the confidence range for the re-estimate of the autumn smolting threshold $\left(L_{\mathrm{h}}^{\mathrm{aut}}\right)$ encompasses the canonical value, we note that predictions using the re-estimate are visibly more faithful to the data than those using the canonical value. Finally, the fry growth density-dependence parameter $\xi$, while numerically small, is significantly different from zero. Its best-fit value implies a reduction of about $40 \%$ in fry growth rate if the burn is fully populated with fry.

\section{Postdicting emigrant production}

A simple re-presentation of the results used to generate Fig. 7 gives us a prediction of the decadal variation of total emigrant production that we can compare with the data (Fig. 8a, solid line). In contrast to the calculation of proportional emigration, this postdiction depends critically on the model inputs in the form of adult spawners, the stock-fry recruitment curve, and the parr mortality, so the generally good correspondence between data and predictions indicates the validity of both the model and the parameter values in Table 1.

However, we note that for cohorts from 2001 onwards, when ova planting was undertaken, the smolt output is considerably underpredicted. This seems likely to result from changes in fry or parr mortality, consequent upon differences between a uniform planted ova distribution and a more clumped natural distribution, or from reduced egg mortality during incubation relative to natural conditions. To illustrate the likely magnitude of the changes involved, we also show (Fig. 8a) the trajectories that would result from cohorts from 2001 onwards having reduced parr mortality ( $m=0.13 \% \cdot$ day $^{-1}$, dotted line) or a stock-recruitment curve that rises more rapidly at low spawner levels $\left(A_{\mathrm{h}}=17\right.$, broken line).

We illustrate a simulation experiment (Fig. 8b) designed to distinguish between year-to-year variability produced by variations in spawner numbers and variations driven by year-to-year temperature changes. We repeat the best-fitting run (Fig. 8a, parameters from Table 1 except that cohorts from 2001 have $A_{\mathrm{h}}=17$ ) but with the temperature cycle in all years set equal to that in 1969 (Fig. 8b, dotted line) or 2003 (Fig. 8b, broken line). We see that both these changes produce changes of around $20 \%$ in smolt production in some years, but neither has any pronounced effect on the predicted trend. We conclude that the decadal temperature trends illustrated (Fig. 4), while clearly implicated in the changes in age at smolting (Fig. 7), have had relatively minor effects on total smolt production.

\section{Discussion}

In this paper, we describe a stochastic model of salmon parr recruitment, growth, survival, and smolting that we have applied to four decades of data from a Scottish upland stream (the Girnock Burn). From this we draw two principal conclusions: first, that trends in age at smolting are compatible with causation by a temperature-dependent growth rate in the form of an activated process with an activation temperature close to that given for Salmo trutta by Elliott (1976); and second, that the remarkably small change in total smolt output, in the context of a $70 \%$ decrease in spawner input, must be ascribed to strong density dependence in ova or fry survival - caricatured in this model by a spawner-fry stock-recruitment relation. This relation appears to have been altered by the ova-planting programme affecting cohorts hatched from 2001 onwards.

We note that the canonical parameter set given in Table 1 contains values that, where they can be compared with biological reality, are broadly reasonable. Interestingly, although the summer von Bertalanffy growth rate scales for fry and parr are similar, the growth probabilities for the two stages are very different. This argues that fry growth proceeds at much the same relative rate as that of parr but is much less variable. In this context, we note observations made at FRS-FL (J. Gilbey, FRS-FL, Pitlochry, PH165LB, Scotland, unpublished data) that suggest that a compensation mechanism operates on alevin growth.

Our model was driven by monthly averaged temperatures at a single station (Littlemill). Recent observations (Malcolm et al. 2002) have shown differences in daily mean temperature of several degrees between this station and the upper reaches of the catchment. However, the upstream temperatures were shown to be highly correlated with those at Littlemill, so we believe that monthly averaged temperatures at Littlemill form a suitable index for temperature trends over the parts of the main stem where maximum spawning activity is located. We also note that in our model, growth rate variability consequent on short-term local variability and spatial heterogeneity are both subsumed within the stochasticity of the growth process.

The activated process form that we have used for the temperature dependence of the growth rate scale, although highly appropriate for the basal metabolic rate that it nominally describes (see Gurney et al. 2007), is incompatible with data, given by both Elliott and Hurley (1997) and Forseth et al. (2001), showing that growth rates plateau at around $18{ }^{\circ} \mathrm{C}$ and begin to drop when temperatures much exceed this value. In waters where such temperatures routinely occur, this aspect of the model would certainly require modification. However, in the Girnock, where weekly average temperatures seldom exceed $18{ }^{\circ} \mathrm{C}$, we do not believe that the robust deviations between observation and postdictions based entirely on temperature-dependent growth are caused by such infelicities. 
Managers of Atlantic salmon (Salmo salar) fisheries face two major concerns. Increased marine mortality (ICES 2006) is jeopardising many populations by reducing the number of adults returning to breed. More recently it has been accepted that climate change is likely to alter the production of salmon smolts from freshwater (McCarthy et al. 2001). The domed nature of the temperature dependence of individual growth performance observed in tank experiments (Elliott and Hurley 1997; Forseth et al. 2001) has led to qualitative suggestions that waters with current average temperatures below $16{ }^{\circ} \mathrm{C}$ will show increased production as a result of increasing temperatures (e.g., Langan et al. 2001), whereas waters with higher current temperatures will show production decreases (e.g., Swansburg et al. 2002). However, we note that these hypotheses depend on an unchanging food environment (or at least a continuing absence of food limitation).

Quantitative assessment of the changes in freshwater production that may flow from water temperature changes requires a detailed understanding of the complex of processes governing the development and survival of salmon parr from ova to smolt. A number of recent studies have examined links in this chain: ova survival and development (Peterson and Quinn 1996); fry growth and survival (Imre et al. 2005); parr growth (Swansburg et al. 2002; Letcher and Gries 2003; Bacon et al. 2005); and smolt quality (Strothotte et al. 2005). However, to understand the overall productivity of freshwater, we need a synthetic framework within which the interaction of the component processes can be evaluated. The model described in this paper provides such a framework, a particular strength being computational efficiency, which is sufficient for Baysian parameter estimation, and thus rigorous hypothesis testing, to be practical.

In our application of this framework, we caricatured the critical density-dependent processes occurring between adult return and the appearance of catchable fry by an empirical stock (fry) - recruitment curve, which may transfer in form to other arenas but the parameters of which we cannot begin to estimate in such arenas without long-term data comparable with that given in Fig. 3. The clearly positive effect of recent manipulations of ova distribution in the Girnock suggests that even in a water with abundant salmon habitat, changes in ova dispersal or survival may fundamentally affect the processes determining the stock-recruitment relation. Taken together with the expense and difficulty of procuring sufficient data to characterize this clearly noisy process, this demonstrates that empirical characterization of the stock-fry transition is not the optimum route to models that generalize well enough to be useful in a policy context.

We believe that the route to a generalisable and thus widely useful model lies in adding to the broad understanding of the parr growth and smolting process embodied in the model described in this paper a similarly detailed understanding of the dynamical details of the growth and survival of the very earliest stages of the life cycle, between deposition of ova in the redd and the appearance of the fry in conventional late-summer surveys. This will require a focused observational, experimental, and theoretical effort but is, we believe, an achievable target.

\section{Acknowledgements}

The authors gratefully acknowledge an anonymous referee of a previous paper who pressingly suggested the use of MCMC methods for this and related problems. Despite our initial scepticism, he (she) was right and we believe that this paper is better for it. The analyses presented in this paper owe much to the early innovative ideas of a number of FRS-FL scientists, including Ian Malcolm and Joe Thorley, and to the hard work and dedication of a larger number of field staff who cheerfully collected data in the most adverse of weather conditions. In this regard, we particularly thank the late Bob Buck, David Hay, Mike Donaghy, Iain McLaren, and Alastair Thorne. Phil McGinnity provided very helpful comments on an earlier draft of this paper.

\section{References}

Bacon, P.J., Gurney, W.S.C., Jones, W., McLaren, I.S., and Youngson, A.F. 2005. Seasonal growth patterns of wild juvenile fish: partitioning among explanatory variables based on individual growth trajectories of Atlantic salmon (Salmo salar). J. Anim. Ecol. 74: 1-11. doi:10.1111/j.1365-2656.2004. 00875.x.

Buck, R.J.G., and Hay, D.W. 1984. The relationship between spawning stock and progeny of Atlantic salmon (Salmo salar) in a Scottish stream. J. Fish Biol. 23: 1-11. doi:10.1111/j.10958649.1984.tb04771.x.

Egglishaw, H.J., and Shackley, P. 1985. Factors governing the production of juvenile Atlantic salmon in a Scottish stream. J. Fish Biol. 27: 27-33. doi:10.1111/j.1095-8649.1985.tb03229.x.

Elliott, J.M. 1976. The energetics of feeding metabolism and growth of brown trout Salmo trutta in relation to body weight, water temperature and ration. J. Anim. Ecol. 45: 923-948. doi: $10.2307 / 3590$.

Elliott, J.M., and Hurley, M.A. 1997. A functional model for the maximum growth of Atlantic salmon parr, Salmo salar, from two populations in north-west England. Funct. Ecol. 11: 592603. doi:10.1046/j.1365-2435.1997.00130.x.

Erkinaro, J., and Niemela, E. 1995. Growth differences between the Atlantic salmon parr, Salmo salar, of nursery brooks and natal rivers in the River Teno watercourse in northern Finland. Environ. Biol. Fishes, 42: 277-287. doi:10.1007/BF00004921.

Forseth, T., Hurley, M.A., Jensen, A.J., and Elliott, M. 2001. Functional models for growth and consumption of Atlantic salmon parr, Salmo salar, from a Norwegian river. Freshw. Biol. 46: 173-186. doi:10.1046/j.1365-2427.2001.00631.x.

Gibson, R.J. 1993. The Atlantic salmon in freshwater: spawning, rearing and production. Rev. Fish Biol. Fish. 3: 39-73. doi:10. 1007/BF00043297.

Grant, J.W.A., Steingrimsson, S.O., Keeley, E.R., and Cunjak, R.A. 1998. Implications of territory size for the measurement and prediction of salmonid abundance in streams. Can. J. Fish. Aquat. Sci. 55(Suppl. 1): 181-190. doi:10.1139/cjfas-55-S1-181.

Gurney, W.S.C., and Veitch, A.R. 2007. The dynamics of size at age variability. Bull. Math. Biol. 69: 861-885. doi:10.1007/ s11538-006-9167-8. PMID:17237914.

Gurney, W.S.C., Tyldesley, G., Wood, S.N., Bacon, P.J., Heath, M.R., Youngson, A., and Ibbotson, A. 2007. Modelling lengthat-age variability under irreversible growth. Can. J. Fish. Aquat. Sci. 64: 638-657. doi:10.1139/F07-039.

Hastings, W.K. 1970. Monte Carlo sampling methods using Markov chains and their applications. Biometrica, 57: 97-109. doi:10.1093/biomet/57.1.97.

Imre, I., Grant, W.J.A., and Cunjak, R.A. 2005. Density dependent growth in young of the year Atlantic salmon Salmo salar in Catamaran Brook, New Brunswick. J. Anim. Ecol. 74: 508-516. 
International Council for the Exploration of the Sea. 2006. Report of the Working Group on North Atlantic Salmon, 4-13 April 2007. ICES CM 2006/ACFM:23.

Jutila, E., Jokikokko, E., and Julkunen, M. 2006. Long-term changes in the smolt size and age of Atlantic salmon, Salmo salar, in a northern Baltic river related to parr density, growth opportunity and postsmolt survival. Ecol. Freshw. Fish, 15: 321-330. doi:10.1111/j.1600-0633.2006.00171.x.

Langan, S.J., Johnston, L., Donaghy, M., Youngson, A.F., Hay, D.W., and Soulsby, C. 2001. Variation in water temperatures in an upland stream over a 30 year period. Sci. Total Environ. 265: 195-207. doi:10.1016/S0048-9697(00)00659-8. PMID:11227266.

Letcher, B.H., and Gries, G. 2003. Effects of life-history variation on size and growth in stream-dwelling Atlantic salmon. J. Fish Biol. 62: 97-114. doi:10.1046/j.1095-8649.2003.00009.x.

Malcolm, I.A., Soulsby, C., and Youngson, A.F. 2002. Thermal regime in the hyporheic zone of two contrasting salmonid spawning streams: ecological and hydrological implications. Fish. Manag. Ecol. 9: 1-10. doi:10.1046/j.1365-2400.2002. 00276.x.

McCarthy, J.J., Canziana, O.F., Leary, N.A., Dokken, D.J., and White, K.S. 2001. Climate change 2001: impacts, adaptation and vulnerability. Contribution of Working Group II to the Third Assessment Report of the Intergovernmental Panel on Climate Change (IPCC), Cambridge University Press, Cambridge, UK.

Metcalfe, N.B. 1998. The interaction between behaviour and physiology in determining life-history patterns in Atlantic salmon (Salmo salar). Can. J. Fish. Aquat. Sci. 55(Suppl. 1): 93-103. doi:10.1139/cjfas-55-S1-93.

Metcalfe, N.B., and Thorpe, J.E. 1990. Determinants of geographic variation in the age of seaward migrating salmon (Salmo salar). J. Anim. Ecol. 59: 131-145.

Metcalfe, N.B., and Thorpe, J.E. 1992. Anorexia and defended energy levels in overwintering juvenile salmon. J. Anim. Ecol. 61: 175-181. doi:10.2307/5520.

Moir, H.J., Soulsby, C., and Youngson, A.F. 1998. Hydraulic and sedimentary characteristics of habitat utilised by Atlantic salmon for spawning in the Girnock Burn, Scotland. Fish. Manag. Ecol. 5: 241-254. doi:10.1046/j.1365-2400.1998.00105.x.

Peterson, N.P., and Quinn, T.P. 1996. Spatial and temporal variation in dissolved oxygen in natural egg pockets of chum salmon in Kennedy Creek, Washington. J. Fish Biol. 48: 131-143. doi:10.1111/j.1095-8649.1996.tb01424.x.

Strothotte, E., Chaput, G.J., and Rosenthal, H. 2005. Seasonal growth of wild Atlantic salmon juveniles and implications on age at smolting. J. Fish Biol. 67: 1585-1602. doi:10.1111/j. 1095-8649.2005.00865.x.

Swansburg, E., Chaput, G., Moore, D., Caissie, D., and El-Jabi, N. 2002. Size variability of juvenile Atlantic salmon: links to environmental conditions. J. Fish Biol. 61: 661-683. doi:10.1111/j. 1095-8649.2002.tb00903.x.

von Bertalanffy, L. 1938. A quantitative theory of organic growth (inquiries on growth laws). II. Hum. Biol. 10: 181-213.

Youngson, A.F., Buck, R.J.G., Simpson, T.H., and Hay, D.W. 1983. The autumn and spring emigrations of juvenile Atlantic salmon, Salmo salar, from the Girnock Burn, Aberdeenshire, Scotland: environmental release of emigration. J. Fish Biol. 23: 625-639. doi:10.1111/j.1095-8649.1983.tb02942.x.

Youngson, A.F., Jordan, W.C., and Hay, D.W. 1994. Homing of Atlantic salmon (Salmo salar) in a tributary spawning stream in a major river catchment. Aquaculture, 121: 259-267. doi:10. 1016/0044-8486(94)90025-6.
Youngson, A.F., Malcolm, I., Thorley, J.L., Bacon, P.J., and Soulsby, C. 2004. Long-residence ground-water effects on incubating salmonid eggs: low hyporheic oxygen impairs embryo development. Can. J. Fish. Aquat. Sci. 61: 2278-2297. doi:10. 1139/f04-217.

\section{Appendix A. The model}

\section{Individuals}

\section{Growth}

Our model characterises individuals by their length $(L)$ and asserts that in an environment with food abundance $(F)$, this length changes irreversibly at a rate

$$
\frac{\mathrm{d} L}{\mathrm{~d} t}=[\alpha \varphi(F)-\mu L]^{+} \text {where } \varphi(F)=\frac{F}{F+F_{H}}
$$

Here, $[x]^{+}$implies $\max (x, 0), \alpha$ is a constant of proportionality, $\mu$ is the length-specific basal metabolic rate (BMR) (i.e., one-third of the weight-specific BMR), and $F_{\mathrm{h}}$ is the half-saturation food abundance.

The key simplifying assumption is that growth rate variability occurs because food abundance, while constant over periods of time $\tau$ (the growth correlation time), varies randomly between individuals in a given growth correlation period and (for a given individual) between successive periods. It is further assumed that for a given individual within a given growth correlation period, the food abundance $(F)$ is either large enough compared with $F_{\mathrm{h}}$ that $\varphi$ can be approximated as unity, or small enough for $\varphi$ to be approximated as 0 , these two eventualities occurring with probability $p$ and $(1-p)$, respectively. This makes it possible to define

(A2) $\quad L_{\infty}=\frac{\alpha}{\mu}$

to represent the asymptotic length of an individual growing indefinitely in a super-abundance of food and hence rewrite eq. A1 as a probabilistic extension of the von Bertalanffy (1938) model, namely

$$
\frac{\mathrm{d} L}{\mathrm{~d} t}= \begin{cases}\mu\left(L_{\infty}-L\right) & \text { with probability } p \\ 0 & \text { with probability } 1-p\end{cases}
$$

Gurney et al. (2007) formally classified individuals using a development index $q$ related to length $(L)$, thus

$$
q=-\ln \left[1-\frac{L}{L_{\infty}}\right] \Leftrightarrow L=L_{\infty}\left[1-\mathrm{e}^{q}\right]
$$

Some elementary algebra, starting from eq. A3, shows that the rate of change of $q$, thus defined, is independent of its current value, i.e.,

$$
\frac{\mathrm{d} q}{\mathrm{~d} t}= \begin{cases}\mu & \text { with probability } p \\ 0 & \text { with probability } 1-p\end{cases}
$$

This property is vital for an efficient population dynamic description (eq. A14), because it ensures that a representation composed of equal-width development index classes can be updated at time intervals chosen so that all members 
of a given class that survive and grow are in the adjacent class at the next update.

Gurney et al. (2007) showed that with constant values of $\mu$ and $p$, the mean length at age predicted by this model asymptotically approaches $L_{\infty}$ with a realised von Bertalanffy growth rate

$$
\gamma=p \mu
$$

We shall thus parameterise our model using a realised growth rate $\gamma$ that affects the behaviour of the mean size at age and a growth probability $p$ that influences the size-atage dispersion.

Gurney et al. (2007) fitted growth patterns with considerable within-year detail by assuming that the growth probability $(p)$ has a high (summer) value $(P)$ between day (of the year) $D_{\mathrm{g}}$ and day (of the year) $D_{\mathrm{w}}$ and a lower (winter) value, which we write as $\omega P$, otherwise. We follow this assumption but recognise that fry live in a distinct environment from parr, which we recognise by assuming that their summer growth probability is $\varphi P$. Recalling that river age is measured from 1 January in the year of hatch, we define fry as individuals the river age of which is less than the day of the year on which the fry growing season ends $\left(D_{\mathrm{w}}^{\mathrm{f}}\right)$. Hence, if a year contains $Y$ days and $a_{y}=a \bmod Y$ represents the day of the year on which the cohort has river age $a$, then we can write the value of $p$ appropriate to an individual aged $a$ as

$$
p_{a}= \begin{cases}\varphi P & \text { if } a<D_{\mathrm{w}}^{\mathrm{f}} \\ P & \text { if } a>D_{\mathrm{w}}^{\mathrm{f}}, a_{y} \geq D_{\mathrm{g}}, \text { and } a_{y} \leq D_{\mathrm{w}} \\ \omega P & \text { otherwise }\end{cases}
$$

Gurney et al. (2007) fitted data on the growth of single cohorts of trout and salmon parr by regarding $L_{\infty}$ and $\mu$ as constants. However, we wish to understand temperaturedriven trends in growth performance, so we need to incorporate temperature effects more explicitly. The energetics of salmonid feeding have been examined by Elliott (1976), who showed that the weight-specific basal metabolic rate of brown trout (Salmo trutta) varies exponentially with temperature. Jones et al. (2002) used the same form in an individual-based growth model for juveniles of a different salmonid species (Atlantic salmon). We shall adopt the same exponential formulation but recognise that fry and parr inhabit distinct environments, have a longer growing season, and exhibit density-dependent growth (J. Thorley, FRS-FL, Pitlochry, PH165LB, Scotland, unpublished data). To incorporate density dependence, we assume that the realised growth rate scale for fry has a maximum value $\eta$ times that for parr and falls linearly as cohort size $\left(N_{a}\right)$ increases. Hence we write realised growth rate of a cohort aged $a$ as

$$
\gamma_{a}= \begin{cases}\left(\eta \gamma_{0}-\xi N_{a}\right) \exp \left[T_{a}^{y} / T_{\mu}\right] & \text { if } a<D_{\mathrm{w}}^{\mathrm{f}} \\ \gamma_{0} \exp \left[T_{a}^{y} / T_{\mu}\right] & \text { if } a>D_{\mathrm{w}}^{\mathrm{f}}, a_{y} \geq D_{g}, \text { and } a_{y} \leq D_{\mathrm{w}} \\ \omega \gamma_{0} \exp \left[T_{a}^{y} / T_{\mu}\right] & \text { otherwise }\end{cases}
$$

where $\gamma_{0}$ is the realised growth rate scale for parr, $\eta$ is the ratio of zero density growth rate scales for fry and parr, $\xi$ is the density-dependence parameter, $T_{\mu}$ is the characteristic temperature, and $T_{a}^{y}$ is the temperature to which cohort $y$ is exposed at age $a$. For a year of length $Y$ days, $T_{a}^{y}$ is related to the river temperature at time $t, T_{t}^{\mathrm{R}}$, by

$$
T_{a}^{y}=T_{y+a / Y}^{\mathrm{R}}
$$

In our application of this model to data obtained in the Girnock Burn, we determine $T_{a}^{y}$ by linear interpolation of monthly averaged temperature observations at Littlemill, which are assumed to apply exactly at the centre day of the month concerned.

\section{Emigration}

Despite considerable observational and theoretical attention, there is still debate about when an individual parr makes the decision to go to sea. It has been suggested (Metcalfe and Thorpe 1992; Thorpe et al. 1998) that an individual that will emigrate in a particular spring run will have changed its growth pattern to accommodate this strategy as early as the previous autumn. However, we have no quantitative evidence for wild Girnock parr that could be used define the parameters for a mechanistic model representing such strategic adjustments, so for simplicity, we assume that individuals that have decided to emigrate will continue to grow normally until they actually leave.

Having taken this view, little if anything further is lost if we simply evaluate the emigration decision at the instant of emigration. Further model simplification can then be achieved by postulating that emigration takes place only at two specific times (i.e., days) of the year, which we denote by $D_{\mathrm{r}}^{\text {aut }}$ and $D_{\mathrm{r}}^{\mathrm{spr}}$ and refer to as the autumn and spring runs, respectively. When comparing predictions with data, we note that the model is predicting the cumulative emigration up to the nominal run day.

Biological processes normally display considerable individual-to-individual variability, so even in the context of the foregoing simplifications, it seems appropriate to take a probabilistic view of the emigration process. We define $e_{q}^{\text {run }}$ as the probability that an individual with development index $q$ will emigrate at the spring or autumn run and choose

$$
e_{q}^{\mathrm{run}}=\varepsilon^{\mathrm{run}}\left(1+\exp \left[\frac{L_{\mathrm{h}}^{\mathrm{run}}-L_{q}}{L_{\mathrm{w}}}\right]\right)^{1}
$$

where run $\in[\mathrm{spr}$, aut], as an appropriate functional form, as it varies from zero when $L_{q}$ is small compared with $L_{\mathrm{h}}^{\text {run }}$ up to $\varepsilon^{\text {run }}$ when $L_{q}$ is large compared with $L_{\mathrm{h}}^{\text {run }}$, with the width of the zone of transition being determined by $L_{\mathrm{w}}$. In line with our decision to regard the size cue for 
emigration as time- and age-independent, we assume that the only difference between autumn and spring runs is the proportion of those large enough to emigrate that actually do so $\left(\varepsilon^{\text {run }}\right)$.

\section{Cohorts and populations}

We regard a population as a sequence of cohorts (year classes) each characterised by the year in which its members were hatched and its age $a$ calculated from 1 January in that year. Our description of the cohort state at age $a$ uses a sequence of development index classes of width $d q$. We use $N_{q, a}^{y}$ to denote the number of individuals in cohort $y$ with development indices in $q \rightarrow d+d q$ (that is lengths in $L_{q} \rightarrow$ $L_{q+d q}$, see eq. A4) when the cohort is aged $a$.

\section{Recruitment}

The history of cohort $y$ is deemed to start on day $D_{\text {hatch }}$ of year $y$ when $R^{y}$ individuals (the survivors of the eggs deposited by the $A^{y-1}$ females that spawned the previous autumn) emerge from the gravel with mean length $L_{\text {hatch }}$ and length variability characterised by coefficient of variation $(\mathrm{CV})$ $C_{\text {hatch. }}$. We now need to relate the cohort recruitment $R^{y}$ to the number of spawning adults $A^{y-1}$.

In Fig. 3, we plot the total number of fry in the Girnock Burn, conventionally estimated from the autumn electrofishing fry survey (Buck and Hay 1984), against the total number of adult females (grilse and multi-sea-winter individuals) spawning in the burn the previous autumn. Survival between spawning and this survey (which normally occurs around day of the year 200) is strongly density-dependent. As the solid line in Fig. 3 shows, we can obtain a satisfactory caricature of this stock-recruitment relation using a shifted logistic function of the form

$$
\begin{aligned}
& F^{y}=\frac{\gamma^{y} F_{0} F_{\max }}{F_{0}+\gamma^{y} F_{\max }} \\
& \text { where } \gamma^{y}=\left(1-\exp \left[-\frac{A^{y}{ }^{1}}{A_{\mathrm{h}}}\right]\right)
\end{aligned}
$$

$F^{y}$ is the number of fry at the autumn survey, $F_{\max }$ is the maximum possible number of fry, $F_{0}$ is the offset needed to make the curve pass through the origin, and $A_{\mathrm{h}}$ is the population of spawners at which the unshifted logistic function reaches $63 \%$ of $F_{\text {max }}$.

Because we have no data that would allow us to test a more complex representation, we arrange that the correct number of fry $\left(F^{y}\right)$ arrive at the autumn survey $\left(D_{\text {elf }}\right)$ by the rather arbitrary device of depositing $R^{y}=F^{y}$ newly hatched individuals into the system on day $D_{\text {hatch }}$ and assuming that while they grow according to the requirements of eqs. A7 and A8, they are immortal until they reach the autumn survey at $D_{\text {elf }}$.

To complete our description of this part of the model, we need to assume an explicit form for the length distribution of the newly emerged fry. In the absence of any other information, we assume a lognormal distribution. Hence, our specification of the initial state of cohort $y$ is

$$
N_{q, a_{\text {hatch }}}^{y}=R^{y} \int_{L_{q}}^{L_{q+d q}} \mathcal{N}_{\mathcal{L}}\left(L_{\text {hatch }}, C_{\text {hatch }}\right) \mathrm{d} L
$$

where $L_{q}$ represents the length of an individual with devel- opment index $q$ (eq. A4) and $\mathcal{N}_{\mathcal{L}}(a, b)$ represents the probability density function for a log-normal distribution with mean $a$ and coefficient of variation $b$.

\section{Growth, survival, and emigration}

The power of characterising individuals by development index instead of length is that the rate of change of $q$ is the same for all individuals in the cohort (eq. A5). Hence, if we update a cohort with current realised growth rate $\gamma_{a}$ and growth probability $p_{a}$ (which implies a basal metabolic rate $\left.\mu_{a}=\gamma_{a} / p_{a}\right)$ from age $a$ to $a+\tau$, where

$$
\tau=\frac{p_{a} d q}{\gamma_{a}}
$$

then an individual that has $q$ in $q \rightarrow q+d q$ at time $t$ and that does not die or emigrate will be found in $q \rightarrow q+d q$ with probability $1-p_{a}$ and $q+d q \rightarrow q+2 d q$ with probability $p_{a}$. Hence, if $S_{a, \tau}^{q}$ is the probability of an individual with development index $q$ surviving from age $a$ to age $a+\tau$ and $E_{q}^{a, \tau}$ is the probability that a similar individual does not emigrate over the same period, then

$$
N_{q, a+\tau}^{y}=S_{a, \tau}\left[\left(1-p_{a}\right) E_{q}^{a, \tau} N_{q, a}^{y}+p_{a} E_{q d q}^{a, \tau} N_{q}^{y} d q, a\right]
$$

Equation A10 defines $e_{q}^{\text {run }}$, the emigration probability for an individual that has development index $q$ at the time of a given run. If the spring run takes place on day (of the year) $D_{\mathrm{r}}^{\mathrm{spr}}$ and the autumn run takes place on day (of the year) $D_{\mathrm{r}}^{\text {aut }}$, then we can see that the probability of not emigrating between $a$ and $a+\tau$ is

$$
E_{q}^{a, \tau}= \begin{cases}1-e_{q}^{\mathrm{spr}} & \text { if } a_{y} \leq D_{\mathrm{r}}^{\mathrm{spr}} \text { and } a_{y}+\tau \geq D_{\mathrm{r}}^{\mathrm{spr}} \\ 1-e_{q}^{\text {aut }} & \text { if } a_{y} \leq D_{\mathrm{r}}^{\text {aut }} \text { and } a_{y}+\tau \geq D_{\mathrm{r}}^{\text {aut }} \\ 1 & \text { otherwise }\end{cases}
$$

Because of systematic uncertainty in the inference of total parr population from electrofishing data discussed above, we shall not test our model against inferred time series of parr abundance. There is thus no reason to model mortality after the autumn fry survey by anything other than a density- and age-independent background rate $m$. Hence, we write the incremental survival of an individual aged $a$ as

$$
S_{a, \tau}= \begin{cases}1 & \text { if } a \leq D_{\text {elf }} \\ \mathrm{e}^{m \tau} & \text { otherwise }\end{cases}
$$

\section{Appendix B. Parameter correlations}

The parameters fitted to the individual cohorts 19972003 are generally only weakly intercorrelated. There is one exception, which we show in Fig. B1, where we see that the baseline growth rate scale $\left(\gamma_{0}\right)$ and the summer-towinter growth rate scale ratio $(\omega)$ are strongly correlated. This happens because the data do not define the winter growth halt very precisely so the fit can achieve coincidence with the points measured during the summer with a variety of winter growth rates - higher winter growth implying lower summer growth (i.e., lower $\gamma_{0}$ ) to match the data.

We see that although all cohorts show the correlation, the 1997, 1998, and 2003 cohorts show the biggest range of $\gamma_{0}$, 
Fig. B1. Correlations between the parr summer realized growth rate scale $\left(\gamma_{0}\right)$ and the winter-to-summer growth rate scale ratio $(\omega)$ in the cohort by cohort fits (a) 1997, (b) 1998, (c) 1999, (d) 2000, (e) 2001, (f) 2002, and ( $g$ ) 2003.

(a)

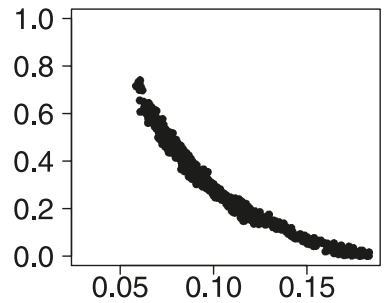

(d)

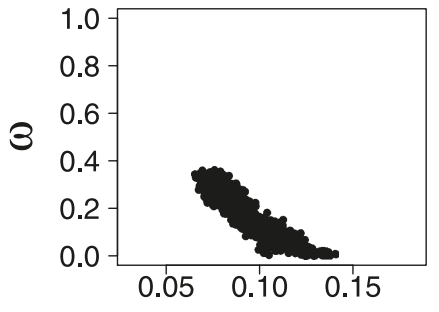

(g)

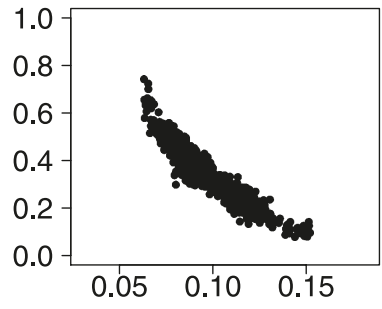

(b)

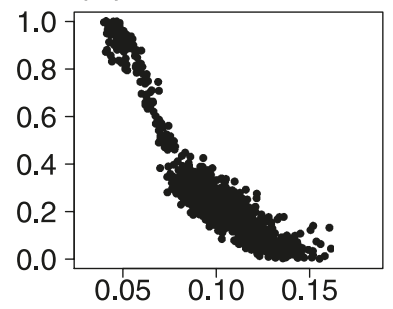

(e)

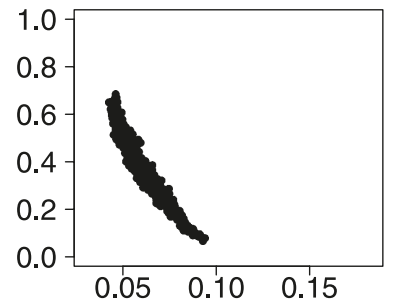

(c)

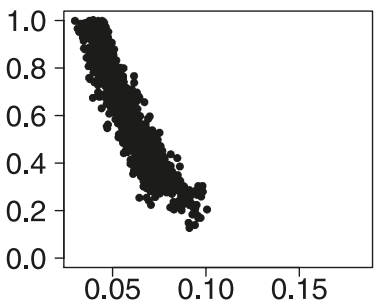

(f)

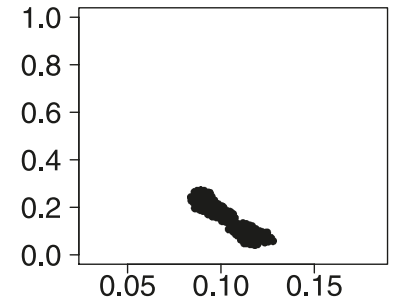

$\gamma_{0}\left(\% \cdot\right.$ day $\left.^{-1}\right)$

whereas 2002 shows the lowest. This reflects the conformation of the data, particularly with regard to the number and timing of the observations of fry size.

\section{References}

Buck, R.J.G., and Hay, D.W. 1984. The relationship between spawning stock and progeny of Atlantic salmon (Salmo salar) in a Scottish stream. J. Fish Biol. 23: 1-11. doi:10.1111/j.10958649.1984.tb04771.x.

Elliott, J.M. 1976. The energetics of feeding metabolism and growth of brown trout Salmo trutta in relation to body weight, water temperature and ration. J. Anim. Ecol. 45: 923-948. doi: $10.2307 / 3590$.

Gurney, W.S.C., Tyldesley, G., Wood, S.N., Bacon, P.J., Heath, M.R., Youngson, A., and Ibbotson, A. 2007. Modelling length- at-age variability under irreversible growth. Can. J. Fish. Aquat. Sci. 64: 638-657. doi:10.1139/F07-039.

Jones, W., Gurney, W.S.C., Speirs, D.C., Bacon, P.J., and Youngson, A.Z. 2002. Seasonal patterns of growth expenditure and assimilation in juvenile Atlantic salmon. J. Anim. Ecol. 71: 916-924. doi:10.1046/j.1365-2656.2002.00679.x.

Metcalfe, N.B., and Thorpe, J.E. 1990. Determinants of geographic variation in the age of seaward migrating salmon (Salmo salar). J. Anim. Ecol. 59: 131-145.

Thorpe, J.E., Mangel, M., Metcalfe, N.B., and Huntingford, F.A. 1998. Modelling the proximate basis of salmonid life history variation with application to the Atlantic salmon, Salmo Salar. Evol. Ecol. 12: 581-599. doi:10.1023/A:1022351814644.

von Bertalanffy, L. 1938. A quantitative theory of organic growth (inquiries on growth laws). II. Hum. Biol. 10: 181-213. 